\section{Abstract:}

\title{
Portfolio of Infrastructure Investments: An analysis of European
}

Infrastructure

\author{
Athina Panayiotou \\ QASER Laboratory \\ University College London \\ London, WC1E6BT \\ athena.panayiotou.12@ucl.ac.uk \\ Tel. 00442076791557 \\ Francesca Medda \\ QASER Laboratory \\ University College London \\ London, WC1E6BT \\ London \\ f.medda@ucl.ac.uk \\ Tel. 00442076791557
}

Infrastructure is receiving much attention in recent years. Investing in infrastructure is particularly effective and suggested for institutional investors such as pension funds due to the characteristics of infrastructure assets. However, robust analytical and empirical analyses that support these investments are limited due mainly to scant empirical data. In this work by collecting relevant data sets on infrastructures, we address two objectives. First, we examine the significance of listed infrastructure sectors and sub-sectors by assessing the investment characteristics and performance of different infrastructure indexes in Europe. The aim here is to determine how an effective and successful infrastructure portfolio should be constructed. Our second objective is to evaluate the strategy of infrastructure investors, in other words, if the investor should invest in a portfolio containing different infrastructure sectors or 
whether it is still possible to obtain diversification benefits by investing in only a single infrastructure sector.

\section{Introduction}

37 Since the early 2000 s, firstly due to the availability of 'cheap' debt and then due to the need for an alternative asset class after the financial crisis, private investors have steadily become interested in infrastructure ${ }^{1}$ investments in Europe, Asia and the United States (Inderst 2009). This asset class has garnered particular attention recently not only because of the distinctive investment characteristics of the sector but also in response to the recent global financial crisis, which have compelled governments to turn to infrastructure investments for economic recovery (RREEF 2011). However, for instance in Europe despite the willingness of many governments to invest in infrastructure as a means of boosting their economies, budgetary constraints imposed by the financial recession on European governments have restrained their enthusiasms towards this investment class (Gomez and Vassalo 2014).

49 Infrastructure investments are not only on the agenda of governments but also private 50 investors are examining these investments with great interest. A study made by Preqin 51 (2013) shows that institutional investors, such as pension funds, will continue to 52 allocate globally, significant amounts of capital to infrastructure assets, thereby gaining 53 exposure to European infrastructure assets in particular. Their analysis demonstrates 54 that starting from 2010, European fundraising levels have doubled year-on-year (Preqin 55 2013) and that $42 \%$ of infrastructure funds are allocated in European infrastructure

\footnotetext{
${ }^{1}$ Infrastructure is often split into two categories: economic and social infrastructure. Economic infrastructure consists of transport services (rail, ports, roads and airports) and other services, such as utilities, energy and telecommunications (Russ et al. 2010), whereas social infrastructure refers to public assets such as hospitals, schools and prisons.
} 
56 (Preqin 2014). We can observe that the annual European infrastructure deal flow has 57 risen significantly due to secure political, regulatory and economic conditions, and to 58 the existence of numerous investible assets with uncorrelated and stable returns (Preqin 59 2013).

60

61 Despite the increased demand for European assets, there are limited specific researches in this area, mainly due to scant empirical data. Most of the existing study concentrates on global infrastructure (RREEF Research 2009) and on the Australian infrastructure market, as it is the most mature market (e.g., Finkenzeller et al. 2010; Peng and Newell 2007; Newell et al. 2011). To date, the research dedicated to the European infrastructure class (Oyedele 2013; RREEF Research 2010; Newell and Peng 2007) often examines listed infrastructure as a whole with limited scrutiny on the economic characteristics of this investment class rather than gives thoroughgoing attention to specific infrastructure sectors. Moreover, most of the aforementioned research assumes that the infrastructure sectors have the same distinctive and attractive investment characteristics; nonetheless there is no specific empirical evidence to support such assertion. Infrastructure is a new vast asset class consisting of many different sectors, each with its own features and historical performance. As Hall et al. (2014) argue one of the major challenges in understanding the long-term performance of infrastructure is the complexity of the sector. Addressing the present knowledge gap will therefore be our objective in this work. Against this background, the objectives of this analysis are twofold. Our first research objective is to understand the investment profile of each infrastructure sector and subsector. Our second and most important aim is to analyze the significance of this 
81 sectorial and sub-sectorial differentiation in investor's investments. To address the first objective, we show how investment characteristics of many different European

83 infrastructure sectors and sub-sectors compare with those of more traditional assets in 84 order to conduct a robust analytical examination of the investment profile of different 85 infrastructure sectors and sub-sectors. In order to address our second aim we examine 86 whether it is beneficial for an investor to build a portfolio of different infrastructure sectors or if it is still possible to obtain diversification benefits by investing in one sector only. We assert that proving the optimality of portfolios, even when investments are

89 focused in a single sector, is important, as in that way the manager of the portfolio will 90 still be able to diversify and yet will also develop a deeper understanding of the behavior 91 of the sector.

93 The paper is structured in the following way: Section 2 reviews the available literature.

94 Section 3 describes the data and methodology used in the present research. A discussion 95 of our analysis results is provided in Section 4 and 5, with conclusions drawn in Section 966.

\section{Literature Review}

99 One key characteristic of infrastructure assets which distinguishes them from all other 100 traditional assets is that they usually operate as a natural monopoly. Under a natural 101 monopoly model, efficient cost optimisation occurs if there is only one firm responsible 102 for the entire output of an industry (Mackay-Fisher 2012). As such, infrastructure assets 103 usually have one or more of the following characteristics: high barriers to entry, 104 economies of scale, inelastic demand, and long-duration (Inderst 2009). These 
105 characteristics convey many attractive investment features to the infrastructure assets, 106 including:

107 - secure stable cash flows,

108 - low correlation to other assets,

109 - inflation hedging properties, and

110 - low correlation with macroeconomic conditions.

111 As a result of the strong interest in infrastructure, there is a range of infrastructure

112 projects, listed infrastructure funds, companies, and unlisted infrastructure funds from

113 which to examine the investment characteristics of this asset class (Oyedele 2013; Peng 114 and Newell 2007). As mentioned above, research is mainly focused on the performance 115 of the global and Australian infrastructure market.

117 According to a performance survey of 100 European Pension Schemes, the expectation 118 of returns for infrastructure assets over a period of 10 years are annualised at $9.5 \%$, 119 lower than private equity but higher than stocks, bonds and cash (Inderst 2009). The 120 asset-liability model of Morgan Stanley Investment Management (2007) compared five 121 different asset classes and found that infrastructure falls behind bonds in terms of 122 volatility and behind private equity in terms of returns. Rickards (2008) also compared 123 the performance of infrastructure assets to equities, emerging markets and cash over a 124 period of 12 years. His results indicated that, on a risk-adjusted return basis, 125 infrastructure outperforms other assets, and he further confirmed that infrastructure's 126 inherent characteristics yield better returns and lower volatility.

128 The first academic study on the performance of infrastructure funds was carried out by 129 Peng and Newell (2007) using both listed and unlisted infrastructure funds in Australia. 
130 Australia has a relevant and available data on infrastructure due to its significant 131 experience with unlisted infrastructure funds. The authors compared the performance 132 of 19 unlisted infrastructure funds, 16 listed infrastructure funds and 16 listed 133 infrastructure companies. They evaluated the performance of funds using returns 134 obtained by UBS for listed infrastructure funds and listed infrastructure companies; and 135 for the unlisted infrastructure funds they used an equally weighted index of 5 out 19 136 major Australian unlisted funds. For the period between Q3. 1995-Q2. 2006, Peng and 137 Newell found average annual returns to be $22.4 \%$ for listed infrastructure and $14.1 \%$ 138 for unlisted infrastructure. Higher returns of listed infrastructure came, however, at the 139 expense of much higher volatility (16.03\%) than all other assets. Whereas unlisted 140 infrastructure fund performance achieved higher average annual returns from Listed 141 Property Trusts (LPTs), Real Estate Investment Trusts (REITs), stocks, direct property, 142 and bonds. The annual volatility of unlisted infrastructure funds was $5.83 \%$, higher than 143 direct property and bonds, but with lower volatility than (LPTs) and stocks.

145 Another interesting study was conducted in 2010 by Colonial First State Global Asset 146 Management (CFS-GAM) which confirmed that listed infrastructure shows higher 147 returns for a 10-year period up to 2006 than unlisted infrastructure, direct property and 148 bonds, but also shows higher volatility. However, the results were not consistent when 149 compared to a shorter 3 or 5-year period (Beeferman 2008). A more recent study carried 150 out by the CFS (2010), using their own index of 5 unlisted infrastructure funds in 151 Australia from 2000-2010, demonstrates that volatility and good risk-adjusted returns 152 compare favorably to other assets. 
154 At this point, we need to notice that one important characteristic of infrastructure assets

155 is that they have low dependence on macroeconomic conditions, thus guaranteeing the 156 resilience of infrastructure returns during periods of low economic activity. Beeferman 157 (2008,) as in the study of Peng and Newell (2007), when calculating the Sharp ratio, 158 has shown that unlisted infrastructure had the highest Sharp ratio of all other asset 159 classes, with the exception of direct property. Newell et al. (2011) in order to account 160 for the effects of the financial crisis, focus on the same unlisted infrastructure funds as 161 CFS study (2010) and Listed infrastructure but extended the dates over a 14-year 162 period, from Q3. 1995 to Q2. 2009. Compared to previous studies, all annual returns 163 were lower for all assets except unlisted infrastructure, which remained unchanged at $16414.1 \%$ with a volatility of $6.27 \%$. Listed infrastructure was the third best performing asset after unlisted infrastructure and direct property with an annual return of $16.7 \%$ 166 and volatility $24.6 \%$. During the financial crisis, specifically during the period between 167 Q2. 2007 and Q2. 2009, all returns from asset classes were negative except for unlisted 168 infrastructure funds and bonds. Importantly, unlisted infrastructure funds showed the 169 highest Sharp ratio of 0.32 while bonds had a Sharp ratio of 0.15 . The study of CFS 170 (2010) also confirms this conclusion. Their index of 5 Australian unlisted funds was 171 less affected by the financial crisis, thereby verifying that unlisted infrastructure 172 performance is robust during an economic downturn.

174 Another pertinent observation is related to the correlation with other assets because 175 diversification can be achieved by investing in assets with a low correlation of returns. 176 The analysis of correlation of returns is heavily constrained by the lack of available 177 data so most studies use listed infrastructure indices. For instance, a study made by 178 Deutsche Bank asset management unit RREEF (2007) evaluates the performance and 
correlations of global returns for 10 years among alternative assets and traditional assets analyzing UBS listed infrastructure. The authors define alternative assets as illiquid assets that have a limited investment history, they are uncommon to use in portfolios and they require specialized manager knowledge. The results show that listed infrastructure has a negative correlation with bonds but it moves with general stock market volatility which shows a moderate correlation between listed infrastructure funds and stocks. It is interesting that listed infrastructure shows higher correlation with other assets compared to unlisted infrastructure. For instance, Peng and Newell (2007) estimate that listed infrastructure had a correlation of 0.21 and 0.38 with equities and bonds respectively, but a correlation of 0.03 with private equity; whereas, unlisted infrastructure has lower correlations with equities and bonds of 0.06 and 0.17 respectively, but a higher correlation of 0.26 with direct property.

The implication of these studies is that infrastructure assets can be used as a shock absorber within a portfolio. Since infrastructure moves independently, it can offer moderate to high returns at times when other assets' returns are decreasing. According to Rickards (2008), private investors would benefit from investing in infrastructure. Given these low correlation results, some analysts have attempted to identify whether including infrastructure assets in a portfolio will lead to a shift in the efficient frontier, giving better risk-return combinations of investment portfolios. In a CSAM (2010) study, results indeed indicate that adding 5\% of listed infrastructure to an institutional pension portfolio of $43 \%$ equities, $24 \%$ fixed income, and $33 \%$ alternatives, would keep the return of the portfolio the same $8.8 \%$ but it reduces the target risk from $11.7 \%$ to 11.4\%. Similarly, CFS (2010) shows that adding 5\% of unlisted infrastructure increases the portfolio return by only $0.1 \%$ but decreasess the risk of the portfolio by $0.5 \%$. 
204 Idzorek and Armstrong (2009) carry out several historical portfolio Markowitz 205 optimizations in addition to a forward-looking optimization, by using several CAPM 206 assumptions and they demonstrate that optimal allocation for infrastructure is between 2070 and 6\%. Finkezeller et al. (2010) by using historical returns and implementing a 208 mean-semi variance approach, calculate the optimal infrastructure allocation at 209 different risk levels. They conclude that low risk investors should include unlisted 210 infrastructure in their portfolios whereas high risk investors should include listed 211 infrastructure.

213 However, as for now research on the European infrastructure market is limited. For 214 instance, in 2010 the RREEF study on the performance of European listed infrastructure assets. The indexes used are UBS Developed Infrastructure \& Utilities Europe, UBS

216 Developed Utilities infrastructure, UBS Developed Infrastructure Europe, and Dow 217 Jones and Brookfield Infrastructure Europe. The study shows that UBS Infrastructure218 only index has the highest return among other asset classes such as stocks, bonds, real 219 estate and private equity. Oyedele et al. (2013) also examine the performance of listed 220 infrastructure over a 10-year period (2001-2010) as well as the significance of listed 221 infrastructure in a mixed-asset portfolio. The work of Oyedele et al. is one of the few 222 studies that also presents some sub-sector analysis performance, as they test the 223 performance of UBS indexes on toll roads, airports, ports, power generation, integrated 224 utilities and integrated regulated utilities. Results of the research indicates that 225 European infrastructure showed an attractive annualized return and an acceptable 226 volatility; and it outperformed more traditional assets such as European stocks and 227 European REITs but performed poorly compared to European bonds. Oyedele et al. 228 (2013) examines the performance of infrastructure during the financial crisis period and 
in so doing he considers differentiation component among the various infrastructure

230 sub-sectors, such as ports. The results show that infrastructure had negative annualized

231 returns and high volatility but the infrastructure sub-sector has an overall better

232 performance of the infrastructure. The portfolio results demonstrate that infrastructure

233 plays a significant role in the optimality of mixed asset portfolios, the incurred benefits

234 however, are more due to enhancing returns rather than reducing risks.

235

236 We can surmise from the literature review that a gap in the literature with regard to the 237 behavior of the different infrastructure sectors and sub-sectors needs to be addressed.

238 In the next sections we will address our two objectives. In so doing, to address our first 239 objective, we assess the investment characteristics and performance of infrastructure 240 indexes in Europe from 2003-2013 for the sector analysis and from 2004-2013 for the

241 sub-sector analysis. Additionally, to address our second objective we examine whether 242 the private sector is better off by investing in an infrastructure portfolio containing a 243 mix of infrastructure sectors or if it still obtains diversification benefits by investing in 244 one specific sector.

\section{Data and Research Methodology}

247 In order to address our two objectives, we have collected data from Thomson Reuters 248 Database. The data include historical time series of monthly returns of European indices 249 over a time span of 11 years (2003-2013) for the infrastructure sector analysis, and 250 weekly returns of European indices over a 10-year time span for the sub-sector analysis 251 (2004-2013). For the sector analysis the assets included are Thomson Reuters European 252 indices in Energy, Utilities, Transport, Telecommunications, Government Bonds, Real 253 Estate, and Stocks. For the sub-sector analysis we use the following listed European 
254 sub-sectors indices: Thomson Reuters Europe Ports Index, UBS Europe Toll Roads 255 Index, UBS Europe Airport Index, Europe Total Market Electricity Index, Thomson 256 Reuters Europe Fossil Fuels Energy Index, MSCI European Power and Electricity 257 Index, Thomson Reuters Renewable Energy Index, and Thomson Reuters European 258 Natural Gas Index. Risk free monthly returns from the same period are collected from 259 the Kenneth R. French Data Library in order to calculate the Sharp Index of each asset. 260 The risk free assets used are Treasury monthly T-bills.

262 The analysis of the European infrastructure asset performance represents our first 263 objective and we develop this analysis on the basis of three aspects. Firstly, we calculate 264 the annualized return, annualized volatility and Sharp Index of each index for the whole 265 period (for the sector analysis from Q1. 2003 to Q4. 2013 and for the sub-sector analysis 266 from Q1.2004 to Q4. 2014). These three measures are used to compare the performance 267 among the different assets over the long-term.

The Sharp Index is calculated by the following formula:

$$
\text { Sharp Index }=\frac{\text { Return }_{i}-\text { Return }_{R_{f}}}{S D_{I}}
$$

271 where:

272 Return $_{i}=$ Return of asset $i$.

273 Return $_{R_{f}}=$ The return of a risk free asset (in this research Treasury monthly T-bills 274 are used).

275 Secondly, diversification benefits among infrastructure assets as well as with other 276 traditional assets (e.g., Stocks, Real Estate and Government Bonds) are evaluated based 277 on the assets' returns matrix correlation. Lastly, since the period examined is interesting as it covers the period of the recent financial crisis, as a last performance test we 
contract our dataset from Q4. 2007 to Q2. 2009 to cover only the years of the financial

280 crisis. The annualised return, annualised volatility and Sharp Index are re-calculated for this 3-year period in order to examine the robustness of listed infrastructure sectors and 282 sub-sectors.

283

284 For the second objective of this paper, i.e. to confirm the best way to construct a 285 portfolio that invests in infrastructure, a portfolio historical analysis is performed using 286 the standard Markowitz $(1952,1959)$ mean-variance portfolio optimisation technique 287 as in Oyedele (2013).

288

289 The return of the portfolio is calculated as follows:

- Return $_{\text {portfolio }}=\sum_{1}^{n} w_{i} * r_{i}$

291 where:

$w_{i}=$ Weight of ith/individual security or asset in portfolio

$293 r_{i}=$ Return of individual security

294 And the variance of the portfolio is calculated by:

295

- Variance $_{\text {portfolio }}=\sum_{i}^{n} w_{i}^{2} * S D_{i j}+2 \sum_{J=1}^{n} \sum_{i=1}^{n} w_{i} w_{j} r_{i j} S D_{i} S D_{j} \quad$ for $\mathrm{i} \neq \mathrm{j}$

296 Where:

- Variance $_{\text {portfolio }}=$ var $_{p}$

- $S D_{P}=\sqrt{v a r_{p}}$

- $r_{i j}=$ Correlation coefficient between the ith and $j$ th variables

- $S D_{i j}=$ Covariance of the ith and $j$ th variables

- $S D_{i}=$ Standard deviation of the ith variable 
After the recent financial crisis, tail-risk analysis has proved to be of vital test to evaluate investors' portfolio risk. For this reason we also estimate the Mean-

304 Conditional Value at Risk (M-CVaR) optimization (Bianchi et al., 2014). The results 305 of the M-(CVaR) optimization are then compared with the Mean-Variance framework 306 to check their robustness. One of the arguments against Markowitz $(1952,1959)$ 307 approach is that the Mean-Variance portfolio measures the risk of the portfolio as the 308 standard deviation; however, this is only valid when the returns are normally 309 distributed. For this reason, we also undertake a second portfolio optimization 310 technique, the M-CVaR portfolio, which uses simulations that do not necessary assume 311 that the distribution of the data is normal. The M-CVaR calculates the highest returns 312 you can obtain for a given level of $\mathrm{CVaR}$ at the $95 \%$ confidence level.

314 The $\operatorname{VaR}_{\alpha}(\mathrm{x})$ for portfolio $\mathrm{x}$, means that with a (1- $\left.\alpha\right)$ probability, the returns will not 315 fall below this level. The conditional value at risk, which is also known as expected 316 shortfall, is the expected loss of the portfolio returns above the $\operatorname{VaR}_{\alpha}(\mathrm{x})$. Following 317 Rockafellar and Uryaser $(2000,2002)$ :

319 The conditional value-at-risk for a portfolio $\mathrm{x} \in \mathrm{X}$, is defined as - $\operatorname{CVaR}_{\alpha}(\mathrm{x})=\frac{1}{1-\alpha} \int_{f(x, y) \geq \operatorname{VaR}_{a(x)}} f(x, y) p(y) d y$,

321 where

- $\quad \alpha$ is the probability level such that $0<\alpha<1$. In this study the probability level is 0.95 .

- $\mathrm{f}(\mathrm{x}, \mathrm{y})$ is the loss function for a portfolio of $\mathrm{x}$ and asset return $\mathrm{y}$.

- $\quad \mathrm{p}(\mathrm{y})$ is the probability density function for asset return $y$. 
The value-at-risk is defined as

- $\operatorname{VaR}_{\alpha}(x)=\min \{\gamma: \operatorname{Pr}[f(x, Y) \leq \gamma] \geq \alpha\}$.

329 The results of the two optimizations are compared in two ways:

- We convert the risk proxies to be able to compare the two portfolios. Using the CVaR portfolio weights we calculate the mean-variance risk of the $10 \mathrm{M}-\mathrm{CVaR}$ efficient frontier portfolios. This will enable us to compare the efficient frontiers of both optimisations and observe any differences.

- By using area plots we visualise the weights of both the mean-variance and the $\mathrm{M}-\mathrm{CVaR}$ and we compare the weights of the chosen assets.

In order to examine how it is most beneficial to construct a portfolio with infrastructure investments, we carry out two different assessments. We first evaluate the significance of European infrastructure in traditional portfolios and then verify whether an investor can still obtain diversification benefits by focusing on a single sector only. We consider two different sectors: Transport, which we identify as a stable sector, and Energy which

341 due to the present innovative but disruptive energy technology we describe as relatively 342 unstable sector, and thus it has less attractive financial performance. We use the 343 GAMS modelling tool to conduct the Mean-Variance optimisations while, the 344 Conditional Value-at-Risk Portfolio Optimisation is estimated in Matlab.

346 We set out to optimise the following portfolios:

347 - Portfolio 1 includes only European traditional assets (Stocks, Real Estate and 348 Government Bonds).

349 - Portfolio 2 includes the same assets as portfolio 1 plus the addition of all $350 \quad$ infrastructure sectors. 
- Portfolio 3 specialises only in transport sub-sector assets (Airports, Ports and Toll Roads) within a traditional portfolio.

- Portfolio 4 specialises only in the energy sub-sector assets (Natural Gas, Electricity, Fossil Fuels, and Renewable Energy) within a traditional portfolio

4. Results: performance analysis of different infrastructure sectors and sub-sectors In this section we address our objectives:

For the first objective, performance analysis of different infrastructure sectors and subsectors, the analysis is divided in two: the sectorial analysis which involves the examination of the performance of four different infrastructure sectors (Energy, Telecommunications, Utilities, and Transport) among traditional assets (Stocks, Real

363 Estate and Government Bonds), and the second part of the analysis which repeats the 364 same performance tests but concentrates specifically on the components of two 365 infrastructure sectors (Energy and Transport). In the second analysis we examine the 366 performance of Natural Gas, Electricity, Fossil Fuels, and Renewable Energy when 367 focussing only on the Energy sector, and the performance of Airports, Ports and Toll 368 Roads when focusing only on the Transport sector. In the sub-sector studies we 369 compare infrastructure assets with the same traditional assets as in the sector analysis 370 (Stocks, Real Estate and Government Bonds). For both analyses the results of the whole 371 dataset are presented first, in order to examine and compare the long-term historic 372 behavior of the assets. We then examine the contracted dataset in order to verify the 373 robustness of the assets during a financial crisis. Lastly, we scrutinize the diversification 374 benefits among the different assets by calculating the inter-correlation matrix for each 375 analysis. 


\section{4 .1 European Infrastructure sector performance analysis}

Table 1 shows the performance of European assets for the period 2003-2013. The four

379 listed infrastructure sectors show significant variation in their performance, proving

380 that infrastructure should not be treated as a singular asset, and that close attention

381 should be paid to the behavior and historical performance of infrastructure's individual sectors.

As can be seen in Table 1, Transport shows a strong performance over the whole sample period, with a return of $9.35 \%$ and volatility at $23.81 \%$. It is the best performing infrastructure asset, with a Sharp Index of 0.334. This is not surprising, as European transport is a very stable sector. Energy instead shows the worst performance of all infrastructure assets, with an annual return of $4.76 \%$ and annual volatility of $21.86 \%$ resulting in a Sharp Index of 0.153 . When comparing the performance of all 390 infrastructure assets with other traditional assets we can conclude that all infrastructure-

391 listed sectors (Energy, Telecommunications, Utilities, and Transport) perform better 392 than Stocks, as illustrated by a higher Sharp Index and they are also less volatile than 393 Real Estate assets. However, Government Bonds show a higher Sharp Index than all of 394 the infrastructure assets.

396 Table 1. Historical performance analysis of European Infrastructure sectors for 397 period Q1. 2003-Q4. 2013.
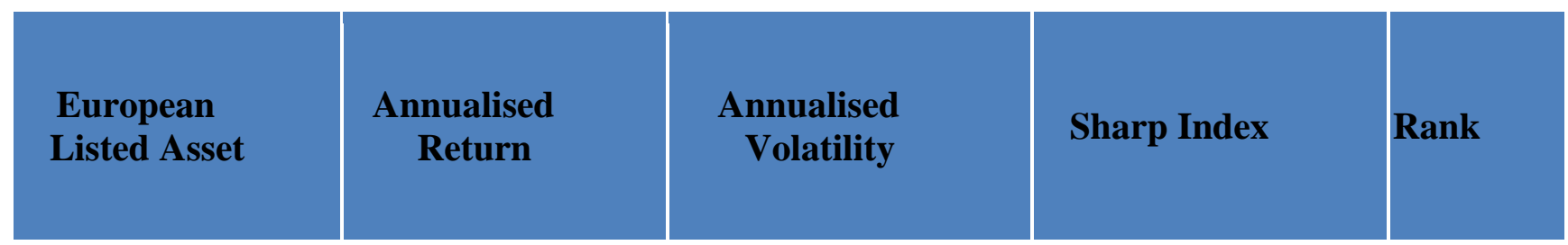


\begin{tabular}{|c|c|c|c|c|}
\hline Energy & $4.76 \%$ & $21.86 \%$ & 0.153 & 6 \\
\hline Telecoms & $5.24 \%$ & $19.21 \%$ & 0.199 & 5 \\
\hline Utilities & $5.96 \%$ & $20.74 \%$ & 0.220 & 2 \\
\hline Transport & $9.35 \%$ & $23.81 \%$ & 0.334 \\
\hline Stocks & $2.55 \%$ & $18.19 \%$ & 0.063 & 7 \\
\hline Real Estate & $6.56 \%$ & $24.47 \%$ & 0.210 \\
\hline Government & & & & \\
\hline Bonds & $5.46 \%$ & $10.33 \%$ & \\
\hline
\end{tabular}

4.2 European Infrastructure sector performance during the financial crisis

As mentioned above, our time period is particularly interesting in that it captures the

401 effects of the recent financial crisis. To allow us to isolate the effect of the financial 402 crisis, and to compare the robustness of listed infrastructure sectors in recessions, we 403 contract our dataset to the crisis period (Q4. 2007-Q2. 2009).

404

405 The results of the annualised return, annualised volatility and Sharp Index for the period 406 of the crisis are presented in Table 2. From our results we can conclude that all assets, 407 except Government Bonds, were severely affected by the crisis. However, all listed 408 infrastructure sectors were affected less negatively than Stocks and Real Estate, as all 409 infrastructure assets have a higher Sharp Index than Stocks and Real Estate. 
411 Table 2. European Infrastructure sector performance analysis during the financial crisis

Q4. 2007-Q2. 2009

\begin{tabular}{|c|c|c|c|c|}
\hline European Listed Asset & \multicolumn{1}{|l|}{$\begin{array}{l}\text { Annualised } \\
\text { Return }\end{array}$} & Volatility & $\begin{array}{l}\text { Sharp } \\
\text { Index }\end{array}$ & Rank \\
\hline Energy & $-25.4 \%$ & $30.4 \%$ & -0.856 & 3 \\
\hline Telecoms & $-30.0 \%$ & $24.6 \%$ & -1.24 & 5 \\
\hline Utilities & $-30.3 \%$ & $31.2 \%$ & -0.992 & 4 \\
\hline Transport & $-28.2 \%$ & $35.1 \%$ & -0.822 & 2 \\
\hline Stocks & $-41.3 \%$ & $30.6 \%$ & -1.37 & 6 \\
\hline Real Estate & $-53.9 \%$ & $37.8 \%$ & -1.44 & 7 \\
\hline Government Bonds & $4.22 \%$ & $14.4 \%$ & 0.247 & 1 \\
\hline
\end{tabular}

\subsection{Diversification Benefits among assets}

415 According to Hall et al. (2014), there is little tradition of thinking cross-sectorally about

416 infrastructure system performance, and this prevents us from understanding the long-

417 term performance of infrastructure. Nevertheless, by calculating the correlation among

418 the monthly returns of all assets, we are able to evaluate if there are any diversification

419 benefits among the different listed infrastructure sectors and also between the different

420 infra-sectors and other traditional assets.

422 The results of the cross asset correlation matrix presented in Table 3 indicate that

423 infrastructure sectors are highly correlated. An explanation of this is given by Hall et 424 al. (2014, p.11), who assert that demand for infrastructure is highly correlated due to

425 the "final demand associated with population and economic growth and because of 426 intermediated demands among infrastructure sectors." For example, a change in 427 demand for electric vehicles would imply a change in demand for the energy sector. 428 This high correlation among the different listed infrastructure sectors proves that there 
is no benefit gained from constructing a portfolio that invests only in different listed

430 infrastructure sectors.

431 All of the listed infrastructure sectors in the table show high correlation with traditional 432 assets as well. The high correlation with Stocks is consistent with the literature, which

433 is not surprising, because in the present study we use indices based on publicly-traded 434 infrastructure companies (Inderst 2009); therefore, in this analysis the low correlation 435 with more traditional assets is not confirmed.

437 Table 3. Cross asset correlation matrix for monthly returns Q1. 2003-Q4. 2013

\begin{tabular}{lccccccc}
\hline & Energy & Telecoms & Utilities & Transport & Stocks & $\begin{array}{c}\text { Real Estate } \\
\text { Government } \\
\text { Bonds }\end{array}$ \\
\hline Energy & 1 & & & & & & \\
Telecoms & 0.693 & 1 & & & & & \\
Utilities & 0.776 & 0.824 & 1 & & & & \\
Transport & 0.720 & 0.772 & 0.845 & 1 & & & \\
Stocks & 0.727 & 0.558 & 0.664 & 0.610 & 1 & & \\
Real Estate & 0.637 & 0.683 & 0.792 & 0.760 & 0.641 & 1 & \\
Government & & & & & & & \\
Bonds & 0.601 & 0.709 & 0.707 & 0.665 & 0.206 & 0.644 & 1 \\
\hline
\end{tabular}

\subsection{Robustness Analysis}

440 To avoid bias, a second index was selected for all traditional assets (Stocks, Real Estate

441 and Government Bonds) as a control in order to check if the obtained results are index-

442 specific. Table 4 shows the performance of the control indexes over the entire dataset.

444 Table 4. Control index historical performance analysis for Q1. 2003-Q4. 2013

\begin{tabular}{|c|c|c|c|c|}
\hline European Listed Asset & \multicolumn{1}{|l|}{$\begin{array}{l}\text { Annualised } \\
\text { Return }\end{array}$} & Volatility & $\begin{array}{l}\text { Sharp } \\
\text { Index }\end{array}$ & Rank \\
\hline Stocks & $3.05 \%$ & $14.26 \%$ & 0.115 & 7 \\
\hline Real Estate & $6.04 \%$ & $23.46 \%$ & 0.197 & 4 \\
\hline Government Bonds & $2.65 \%$ & $7.28 \%$ & 0.170 & 5 \\
\hline
\end{tabular}


446 Nearly all of our conclusions are again confirmed in the robustness analysis. All

447 infrastructure sectors perform better than Stocks, and all infrastructure sectors, except

448 Transport are less volatile than Real Estate. In addition, all infrastructure sectors except

449 Energy have a higher Sharp Index than Real Estate. Government Bonds are still the less

450 volatile asset, however the control index that was used for Government Bonds shows a

451 much lower return. Thus, in the robustness analysis, Government Bonds are not the best

452 performing asset; they are outperformed by all infrastructure assets apart from Energy.

453

454 Table 5. Control index cross asset correlation matrix for monthly returns Q1. 2003-

455 Q4. 2013

Energy Telecoms Utilities Transport Stocks Real Estate Government

\begin{tabular}{lccccccc}
\hline & Energy & Telecoms & Utilities & Transport & Stocks & Real Estate & $\begin{array}{c}\text { Government } \\
\text { Bonds }\end{array}$ \\
\hline Energy & 1 & & & & & & \\
Telecoms & 0.693 & 1 & & & & & \\
Utilities & 0.776 & 0.824 & 1 & & & & \\
Transport & 0.720 & 0.772 & 0.845 & 1 & & & \\
Stocks & 0.713 & 0.627 & 0.705 & 0.668 & 1 & & \\
Real Estate & 0.663 & 0.699 & 0.809 & 0.776 & 0.684 & 1 & 1 \\
Government & & & & & & & \\
Bonds & 0.063 & 0.198 & 0.160 & 0.180 & 0.103 & 0.059 & \\
\hline
\end{tabular}

457 In the robustness analysis the cross asset correlation matrix is calculated and results are

458 given in Table 5. Notably, we can confirm that infrastructure assets are highly

459 correlated with Stocks and Real Estate, but we also observe low correlation with

460 Government Bonds in the robustness analysis. This finding indicates that there are

461 diversification benefits with infrastructure sectors and Government Bonds in a

462 portfolio.

463

$464 \quad 4.5$ European Infrastructure sub-sector analysis 
We next set out to examine the differences between sub-sector assets. The sub-sectors of two different infrastructure sectors (Energy and Transport) have been chosen for our

467 sub-sector analysis. The two sectors are particularly interesting because they behave 468 very differently. The Energy sector is highly changeable, not only in terms of 469 performance, but also due to an unstable regulatory framework (e.g., EU environmental 470 regulation, national renewable energy incentives, feed-in tariffs) which results in 471 higher political risk; whereas the Transport sector represents a relatively stable sector 472 with a fairly stable regulatory framework.

474 The results of the long-term performance of the Energy sector are presented in Table 6.

475 In the European Energy's sub-sector performance analysis we notice that Electricity 476 was the best performing asset over the period examined, with a Sharp Index of 0.258.

477 However, Fossil Fuels and Renewable Energy performed the worst of all other sub478 sectors, with Sharp Indexes of 0.036 and 0.007 , respectively. When we compare them 479 to the traditional assets, we observe that all Energy sub-sectors, apart from Renewable 480 Energy, show lower volatility than Real Estate. But Government Bonds have the lowest 481 volatility of all of the assets.

483 Table 6. European Infrastructure Energy sub-sector historical performance analysis

484 for Q1. 2004-Q4. 2013.

\begin{tabular}{|c|c|c|c|c|}
\hline European Listed Asset & $\begin{array}{c}\text { Annualised } \\
\text { Return }\end{array}$ & $\begin{array}{c}\text { Annualised } \\
\text { Volatility }\end{array}$ & Sharp Index & $\begin{array}{c}\text { Performance } \\
\text { Rank }\end{array}$ \\
\hline Natural Gas & $5.27 \%$ & $18.03 \%$ & 0.200 & 3 \\
\hline Electricity & $6.74 \%$ & $19.72 \%$ & 0.258 & 1 \\
\hline Fossil Fuels & $2.62 \%$ & $26.76 \%$ & 0.036 & 6 \\
\hline
\end{tabular}




\begin{tabular}{|c|c|c|c|c|}
\hline Renewable Energy & $1.89 \%$ & $33.82 \%$ & 0.007 & 7 \\
\hline Stocks & $3.65 \%$ & $19.69 \%$ & 0.101 & 4 \\
\hline Real Estate & $3.90 \%$ & $27.90 \%$ & 0.080 & 5 \\
\hline Government Bonds & $4.01 \%$ & $10.89 \%$ & 0.215 & 2 \\
\hline
\end{tabular}

486 The Transport sub-sector analysis results are presented in Table 7. In the table we can 487 see that Ports, shown by its high Sharp Index of 0.386 , is the best performing asset. 488 Airports also shows a good Sharp Index of 0.308. In contrast, the performance of Toll 489 Roads is much worse that Airports and Ports, with a Sharp Index of 0.117. This is 490 expected, as Ports and Airports not only obtain revenue from their transport services 491 but also from other services in and around airports and ports (i.e., restaurants, shops 492 and so forth). In contrast, most Toll Roads accrue all their revenue solely from transport 493 demand. Despite this observation, however, research conducted by Gomez and Vassalo 494 (2014) showed that in all European countries the revenues generated from road charges 495 exceed road expenditures, with enough money remaining to also subsidise other 496 policies.

In comparison with the more traditional assets, we observe that all of Transport's subsectors (as with the Energy sector) show lower volatility than Real Estate. Furthermore, 500 in the Transport analysis, Government Bonds show the lowest volatility of all sectors 501 as well.

503 Table 7. European Infrastructure Transport sub-sector historical performance 504 analysis for Q1. 2004-Q4. 2013 


\begin{tabular}{|c|c|c|c|c|}
\hline $\begin{array}{c}\text { European Listed } \\
\text { Asset }\end{array}$ & $\begin{array}{c}\text { Annualised } \\
\text { Return }\end{array}$ & $\begin{array}{c}\text { Annualised } \\
\text { Volatility }\end{array}$ & Sharp Index & Performance Rank \\
\hline Airports & $7.90 \%$ & $20.26 \%$ & 0.308 & 2 \\
\hline Ports & $11.06 \%$ & $24.33 \%$ & 0.386 & 1 \\
\hline Toll Roads & $4.20 \%$ & $21.73 \%$ & 0.117 & 4 \\
\hline Stocks & $3.65 \%$ & $19.69 \%$ & 0.101 & 5 \\
\hline Real Estate & $3.90 \%$ & $27.90 \%$ & 0.080 & 6 \\
\hline Government Bonds & $4.01 \%$ & $10.89 \%$ & 0.215 & 3 \\
\hline
\end{tabular}

4.6 European Infrastructure sub-sector performance during the financial crisis

507 In this section we repeat the analysis of the previous section but with a shorter dataset

508 to capture only the period of the financial crisis. Analysis results are shown in Table 8.

509 The performance of the infrastructure sub-sectors during the years of the financial crisis

510 is consistent with the infrastructure sector results. All of the infrastructure sub-sectors

511 were less negatively affected by the financial crisis than Real Estate and Stocks. We

512 can here point up the robustness of infrastructure investments during a downturn in

513 macroeconomic conditions. However, none of the infrastructure sub-sectors was more

514 robust than Government Bonds, which consistently showed the best performance of all

515 the assets during the crisis, with a positive Sharp Index of 0.22.

516

517 Table 8. European Infrastructure sub-sector performance analysis during the financial

518 crisis Q4. 2007-Q2. 2009

\begin{tabular}{|l|l|}
\hline European Listed Asset & Sharp Index \\
\hline Natural Gas & -0.82 \\
\hline Electricity & -0.96 \\
\hline
\end{tabular}




\begin{tabular}{|l|l|}
\hline Fossil Fuels & -0.60 \\
\hline Renewable Energy & -0.85 \\
\hline Airports & -0.70 \\
\hline Ports & -1.10 \\
\hline Toll Roads & -1.05 \\
\hline Stocks & -1.09 \\
\hline Real Estate & -1.17 \\
\hline Government Bonds & 0.22 \\
\hline
\end{tabular}

521 As has been emphasised in this study, when setting out to understand the behavior of

522 infrastructure systems, it is crucial to recognize the interdependence among the

523 different infrastructure assets. In this section we assess the diversification benefits of

524 both Transport and Energy sectors in order to evaluate whether correlation benefits

525 exist in single infrastructure sectors, and if so, calculate the benefit in each sector.

526 The results for the Energy and Transport sector are presented in Tables 9 and 10,

527 respectively. Generally, we observe in both sectors high correlation among all Energy

528 and Transport infrastructure sub-sectors with Stocks and Real Estate. However, for

529 some assets we find low correlation with Government Bonds. These results are also 530 consistent with our sector robustness analysis.

532 In relation to the correlation among the sub-sectors, however, we observe that there is 533 indeed some low correlation within the Transport and Energy sub-sectors; this finding 534 indicates that an investor can obtain diversification benefits, even when investing only 535 in the Transport or Energy sector. 
536 Table 9. Cross asset correlation matrix for Energy sub-sector monthly returns

Q1. 2004-Q4. 2013

\begin{tabular}{|c|c|c|c|c|c|c|c|}
\hline & $\begin{array}{l}\text { Fossil } \\
\text { Fuels }\end{array}$ & $\begin{array}{c}\text { Renewable } \\
\text { Energy }\end{array}$ & $\begin{array}{c}\text { Natural } \\
\text { Gas }\end{array}$ & Electricity & Stocks & $\begin{array}{l}\text { Real } \\
\text { Estate }\end{array}$ & $\begin{array}{c}\text { Government } \\
\text { Bonds }\end{array}$ \\
\hline Fossil Fuels & 1 & & & & & & \\
\hline Renewable & & & & & & & \\
\hline Energy & 0.688 & 1 & & & & & \\
\hline Natural Gas & 0.559 & 0.475 & 1 & & & & \\
\hline Electricity & 0.726 & 0.722 & 0.523 & 1 & & & \\
\hline Stocks & 0.797 & 0.729 & 0.488 & 0.825 & 1 & & \\
\hline $\begin{array}{l}\text { Real Estate } \\
\text { Government }\end{array}$ & 0.734 & 0.652 & 0.485 & 0.658 & 0.779 & 1 & \\
\hline Bonds & 0.427 & 0.260 & 0.335 & 0.199 & 0.155 & 0.461 & 1 \\
\hline
\end{tabular}

539 Table 10. Cross asset correlation matrix for Transport sub-sector monthly returns

540 Q1. 2004-Q4. 2013

\begin{tabular}{lcccccc}
\hline & Ports & Airports & $\begin{array}{c}\text { Toll } \\
\text { Roads }\end{array}$ & Stocks & $\begin{array}{c}\text { Real } \\
\text { Estate }\end{array}$ & $\begin{array}{c}\text { Government } \\
\text { Bonds }\end{array}$ \\
\hline Ports & 1 & & & & & \\
Airports & 0.362 & 1 & & & & \\
Toll roads & 0.390 & 0.648 & 1 & & & \\
Stocks & 0.425 & 0.686 & 0.873 & 1 & & \\
Real Estate & 0.456 & 0.685 & 0.710 & 0.779 & 1 & \\
Government & & & & & & \\
Bonds & 0.294 & 0.460 & 0.245 & 0.209 & 0.516 & 1 \\
\hline
\end{tabular}

542 After having analyzed our first objective, we can confirm that infrastructure is

543 comprised of many different heterogeneous assets, each with its own specific

544 performance. As a consequence, we argue that fund managers should therefore be

545 experts in specific sector and sub-sector elements of an infrastructure investment

546 package in order to deeply comprehend the performance and behavior of their

547 investments.

548

549 5. Results: How to construct a portfolio of infrastructure investment 
550 In this section we examine how to design an infrastructure investment portfolio,

551 objective 2; four different portfolios are therefore analyzed:

552 - Portfolio 1 includes only European traditional assets (Stocks, Real Estate and 553 Government Bonds).

554 - Portfolio 2 includes the same assets as portfolio 1 plus the addition of all 555 infrastructure sectors.

556 - Portfolio 3 specialises only in transport sub-sector assets (Airports, Ports and Toll $557 \quad$ Roads) within a traditional portfolio.

558 - Portfolio 4 specialises only in the energy sub-sector assets (Natural Gas, 559 Electricity, Fossil Fuels, and Renewable Energy) within a traditional portfolio

560 The results of the four different portfolio scenarios are presented in the Mean- Variance 561 framework and then compared with the M-CVaR optimisation. In relation to objective 562 2, what is of interest to us for each scenario in the Mean-Variance Framework is 563 whether we achieve a higher Sharp Index by combining different assets instead of 564 investing only in the best performing asset of each scenario.

565

\subsection{European Portfolio analyses with and without infrastructure} - Portfolio 1 includes only European traditional assets

568 By investing only in Government Bonds gives a Sharp Index of 0.392, while investing 569 only in Real Estate or only in Stocks gives a Sharp Index of 0.210 and 0.063 , 570 respectively. By creating a portfolio that combines Stocks, Real Estate and Government 571 Bonds, one cannot achieve a Sharp Index higher than if one were to invest only in 572 Government Bonds; this result proves that in terms of the Sharp Index ratio, it is always 573 more beneficial to invest only in Government Bonds than to combine a portfolio of 574 different traditional assets. However, depending on the risk attitude of an investor, one 
can combine the three traditional assets to achieve either a lower risk by accepting a

576 lower return or if more risk-loving to accept a higher risk for a higher return (Efficient

577 Portfolio Frontiers can be found in the Appendix).

- Portfolio 2 includes the same assets as portfolio 1, plus the addition of all listed infrastructure sectors

581 Investing in a multi-asset portfolio that combines traditional European assets and listed

582 infrastructure sectors is clearly beneficial. As depicted in Figure 1, by including

583 infrastructure in a traditional European portfolio during the period 2003-2013 provides

584 an outward shift in the efficient frontier. The implication here is that, for the same

585 amount of risk, investors can obtain higher returns.

587 The portfolio that maximises the Sharp Index invests in Transport infrastructure and 588 Government Bonds only, thereby achieving a volatility of $12.1 \%$ and a return of $6.29 \%$, 589 resulting in a Sharp Index of (0.402). By including infrastructure in a traditional 590 portfolio, one can obtain a higher Sharp Index than by investing in any asset on its own.

591 It is noteworthy that in none of the efficient frontiers is it optimal to create a portfolio 592 that invests in many infrastructure sectors. This finding verifies our earlier observation 593 that there are no diversification benefits between different listed infrastructure sectors.

595 Figure 1. Efficient frontiers for Portfolios 1 and 2 


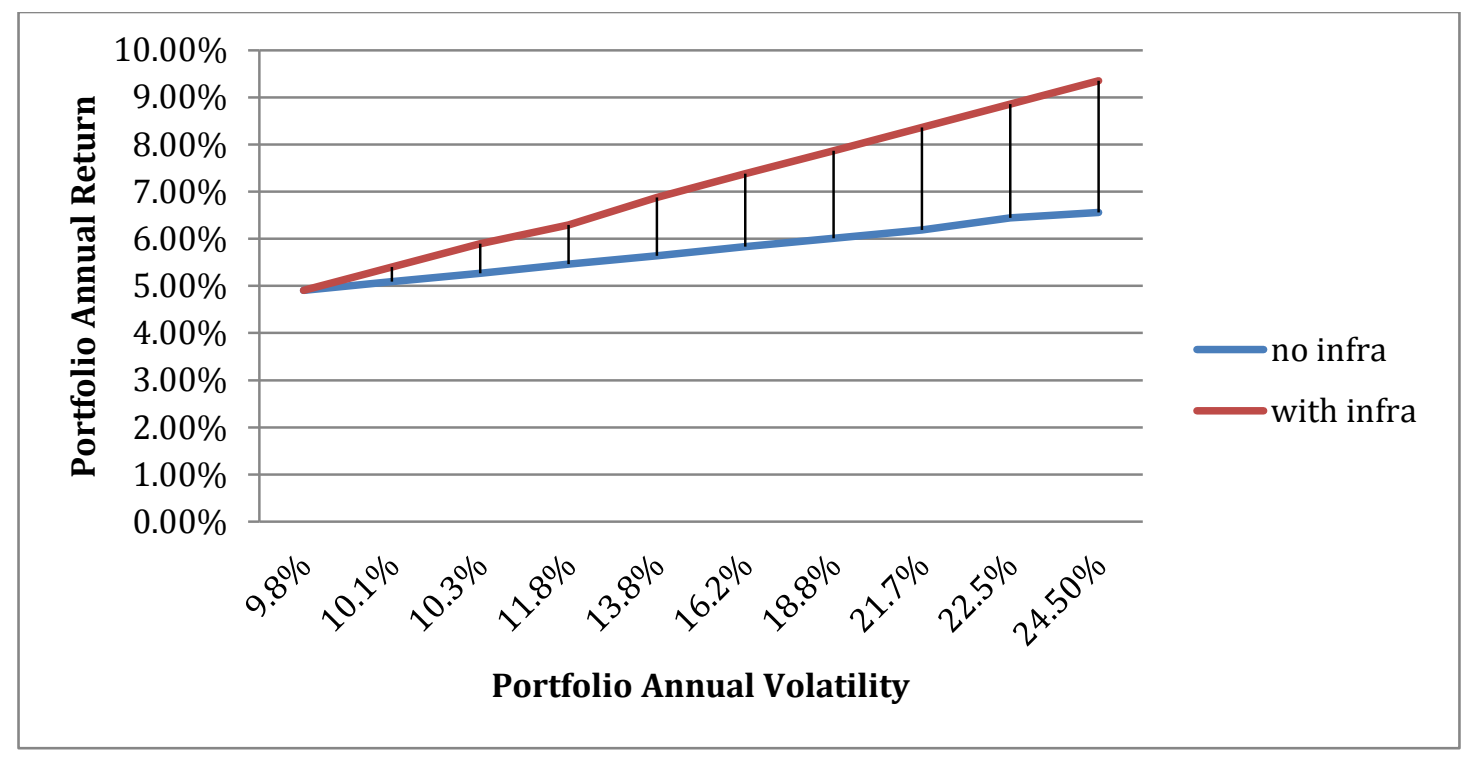

598 As a sensitivity analysis, we undertook a second optimization technique, the M-CVaR 599 optimization, to check our results (Efficient Portfolio Frontiers can be found in the 600 Appendix). To compare the two optimizations, we calculate the monthly mean-variance 601 risk using the weights of the M-CVaR optimization to convert from one risk to the 602 other. This enables us to convert the efficient frontiers of the M-CVaR optimization to 603 a mean-variance plot. Thus, as illustrated in Figure 2, we draw the Mean-Variance 604 Portfolio Efficient Frontiers for both techniques and compare the differences. From 605 Figure 2, one can observe that our Mean-Variance portfolio results are quite robust as 606 the two frontiers are very similar with some differences at the lower level of the 607 frontiers.

608

609 Figure 2. Efficient frontiers for the Mean-Variance and M-CVaR optimization 


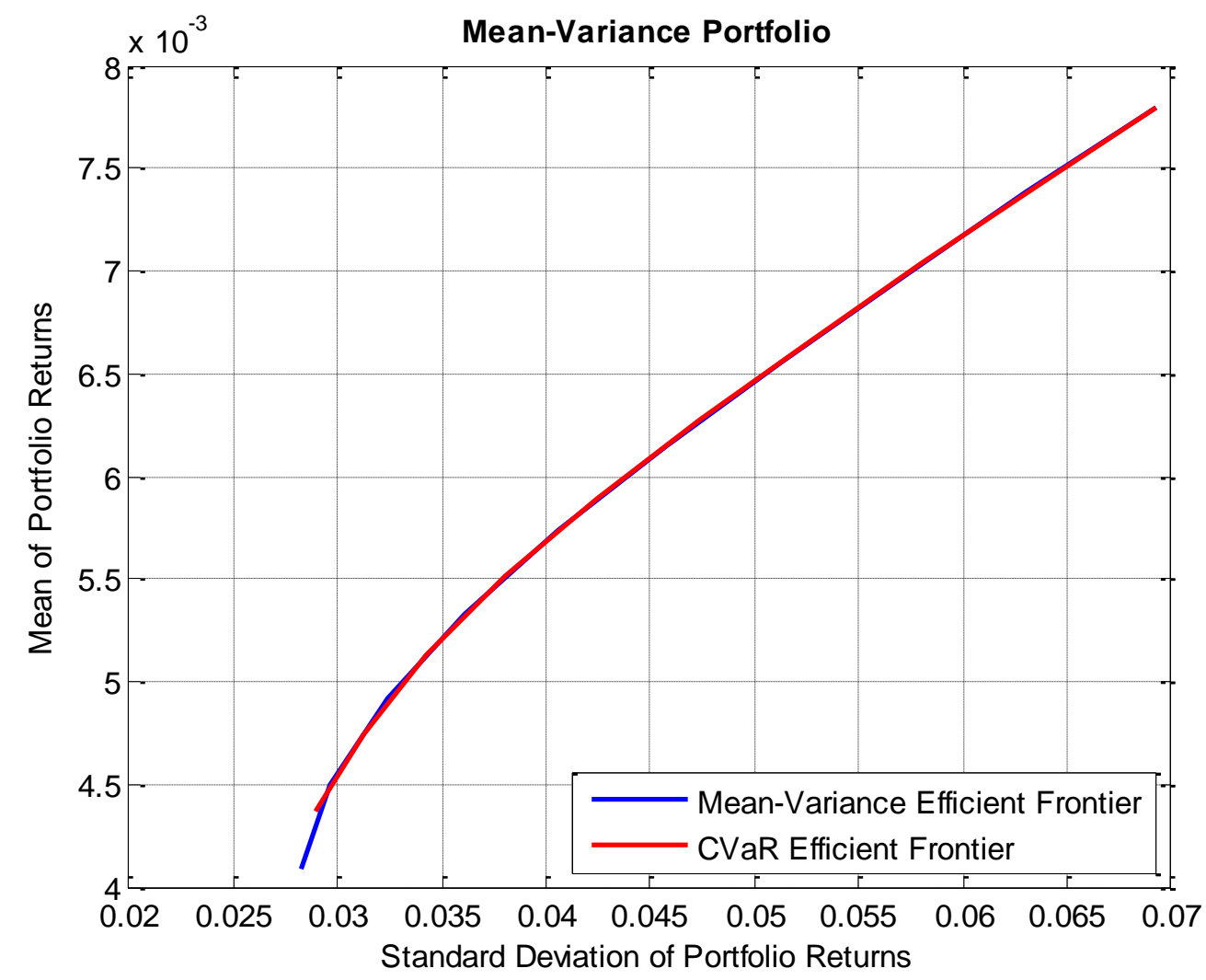

611 The second test that we perform is to compare the weights of the assets in the efficient 612 portfolios of the two optimizations. Figure 3 visualizes the weights of both 613 optimizations using area plots. The only difference observed, in the allocation of the 614 assets between the two optimizations, is that the Mean-Variance optimization gives 615 more weight to Stocks than the M-CVaR optimization. However, we can observe that 616 both optimizations choose to invest in the same assets, which are Government Bonds, 617 Transportation and Stocks. Thus, in conclusion we observe that infrastructure is a good 618 addition to a traditional portfolio and that sectors do not mix in the construction of 619 optimal portfolios is confirmed.

621 Figure 3. Weights Comparison for Portfolios Mean-Variance and M-CVaR 622 optimization 

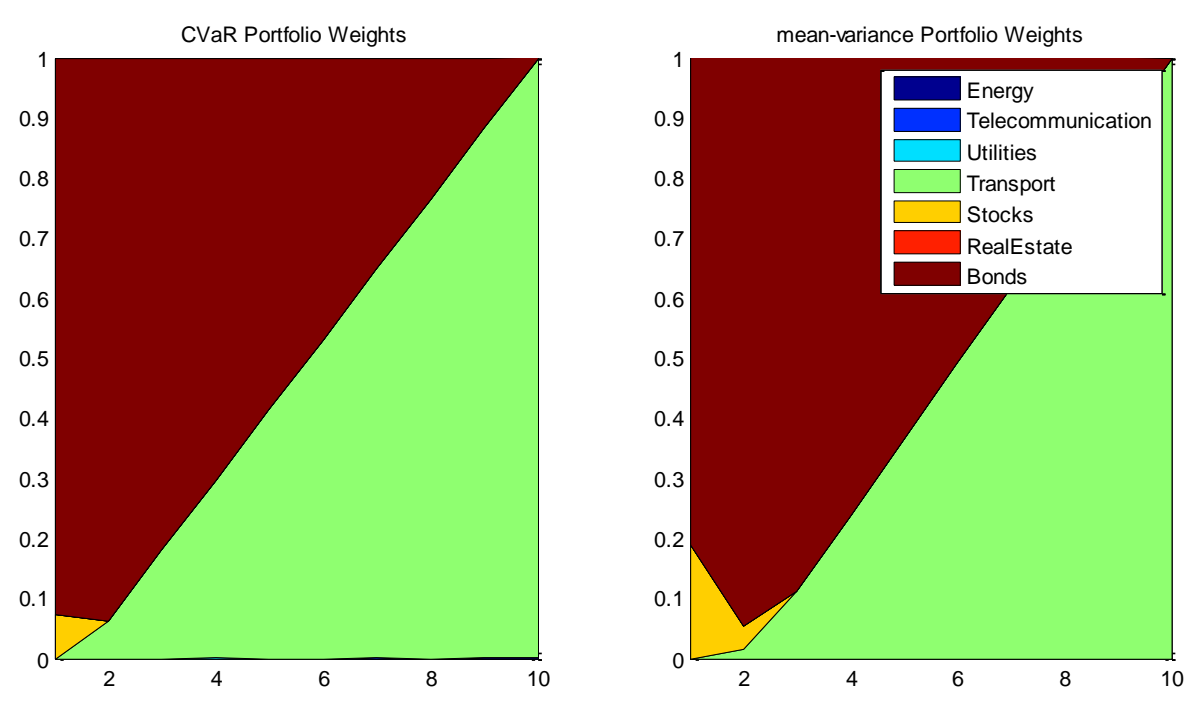

5.2 Sub-sector Portfolio Analysis

626 The results of the previous portfolio scenario show that in European infrastructure

627 investment it is not optimal to create a portfolio that invests in various infrastructure

628 sectors. For this reason, in the third and fourth portfolios we evaluate the diversification

629 benefits that exist by investing in a single infrastructure sector alone. As mentioned

630 above, we have chosen to focus on the Energy and Transport sectors because we are

631 interested in detecting the difference between investing only in a stable sector, such as

632 Transport (where political risks are fewer) compared with the relatively new and

633 unstable Energy sector.

634

- Portfolio 3 specialises only in energy sub-sector assets (Natural Gas, Electricity, Fossil Fuels, Renewable Energy)

638 For the third scenario we construct a portfolio, which includes only Energy sub-sector 639 assets within a traditional portfolio. 
641 As we have seen in the correlation analysis, there are modest diversification benefits in 642 the Energy sector. The portfolio that maximises the Sharp Index, as can be seen by 643 Figure 4, invests $60.6 \%$ in Government Bonds, 32.1\% in Electricity, and $7.29 \%$ in 644 Natural Gas. The highest Sharp Index achieved is 0.311 which is higher than the Sharp 645 Index obtained by investing in any single asset. The optimal portfolio annual return is $6465.02 \%$ and the annual volatility is $10.8 \%$. We observe that sectors such as Renewable 647 Energy and Fossil Fuels are not included in the optimal portfolio; this observation may 648 be because certain sectors are over-valued by the market. However, there are many 649 possible explanations for the exclusion of Renewable Energy and Fossil Fuels, such as 650 government intervention or the ethics and values of the individual fund.

651

652 Figure 4. Optimal Portfolio in the Optimisation of the Energy sector

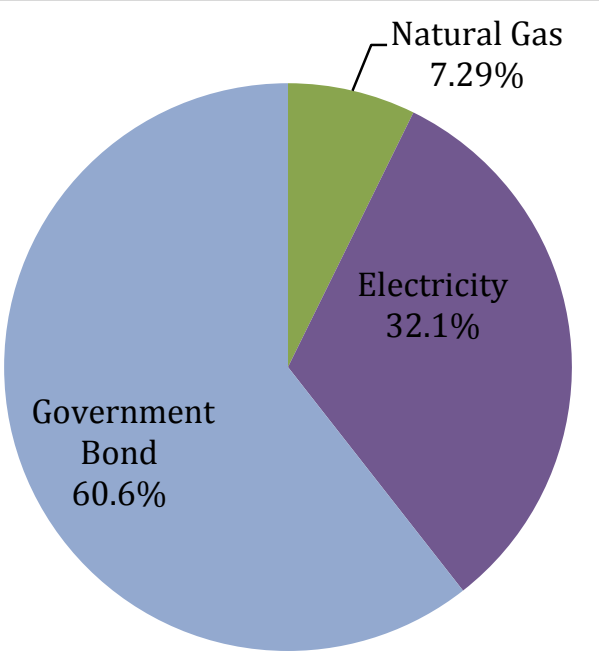

Fossilfuels

- Renewable Energy

NaturalGas

Electricity

Stocks

RealEstate

GovernmentBonds

654 To validate the results above, Figure 5 shows the comparison of the weekly mean 655 variance efficient frontiers of the Mean-Variance Portfolio and the M-CVaR 656 optimisation. The Figure illustrates that some small differences exists between the two 657 optimizations, and this holds especially true for lower levels of portfolio returns. 

robust.

660

661 Figure 5. Efficient frontiers for Portfolios Mean-Variance and M-CVaR optimization

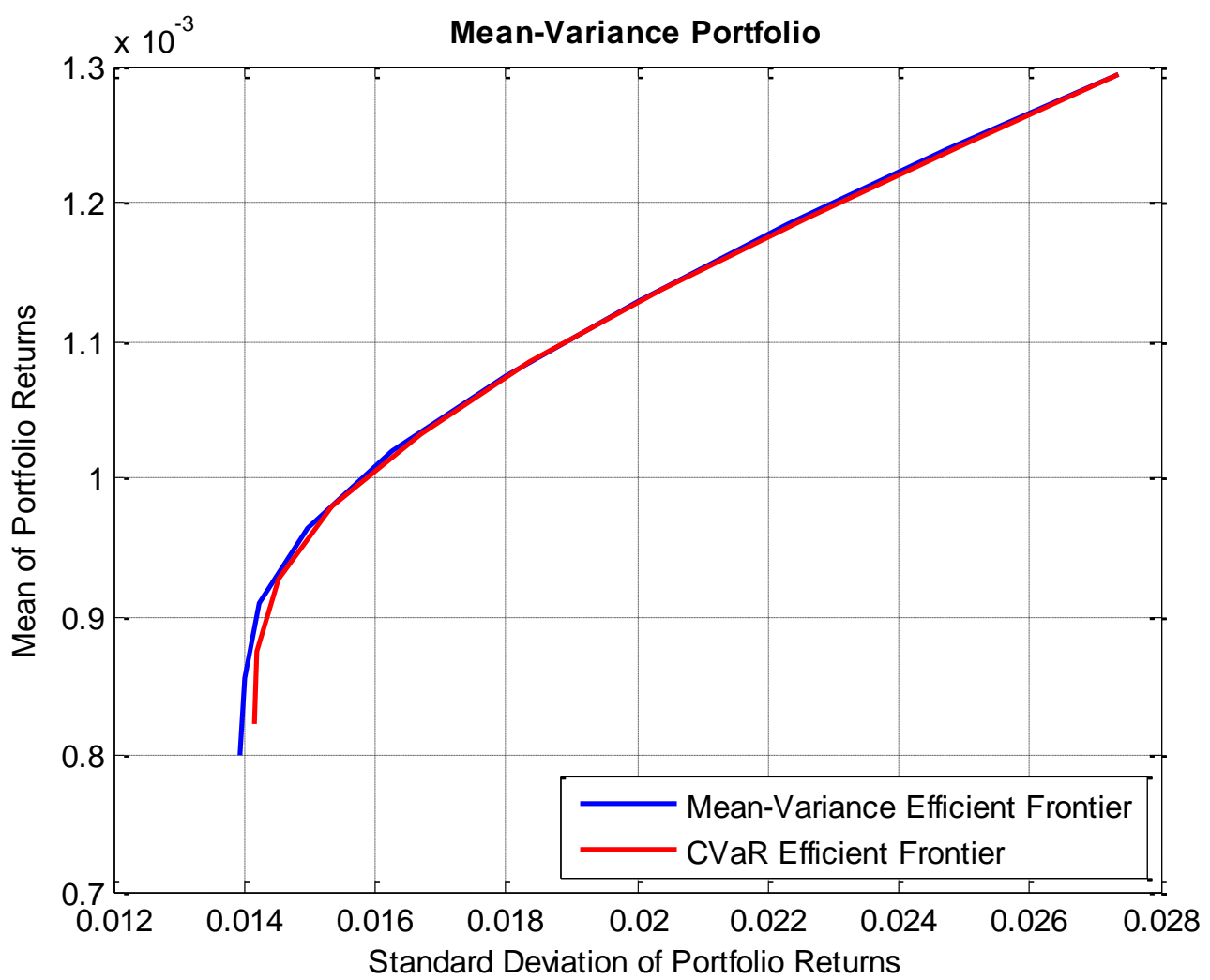

664 When comparing the weights of the two optimizations, we observe that using the M-

665 CVaR optimization invests in the same assets as the Mean-Variance optimization, 666 which are: Government Bonds, Gas, Electricity and Stocks. The allocation in certain 667 assets differs as can be seen from Figure 6. In the M-CVaR optimization more is invested in Gas and less in Stocks than the Mean-Variance portfolio weights. The Appendix depicts the differences present in the first portfolios of the efficient frontier 670 and this explains the differences of the frontiers in the lower level of return/risk ratio.

671 However, since our results are analytically significant we can confirm our conclusion 672 that an investor can still benefit even if he/she focuses on a single infrastructure sector. 
674 Figure 6. Weight Comparison for Portfolios Mean-Variance and M-CVaR 675 optimization

676
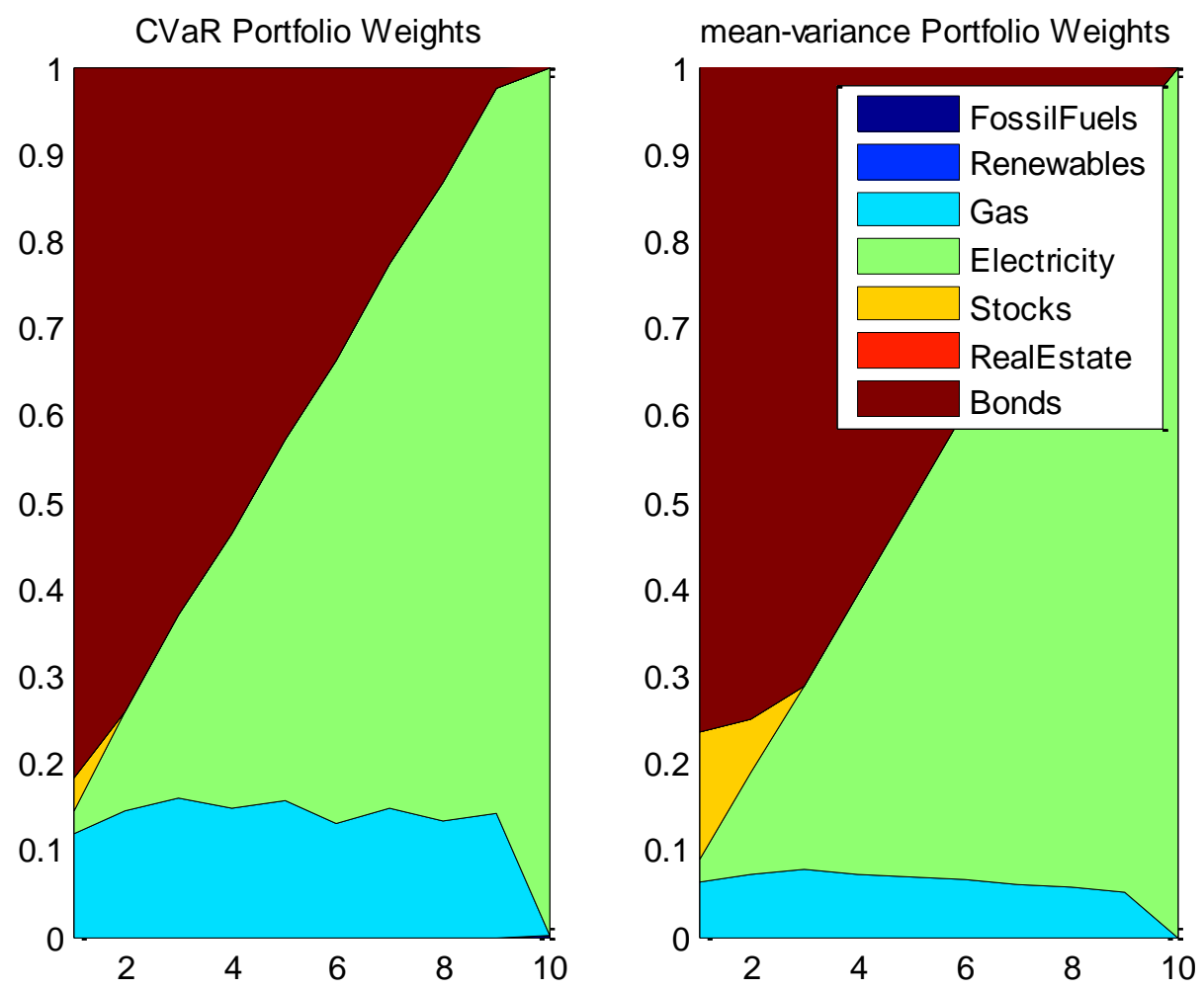

- Portfolio 4 specialises only in transport sub-sector assets (Airports, Ports and

681 In the last considered portfolio, we evaluate the diversification benefits gained by 682 investing only in the Transport sector. For this reason we construct a portfolio that 683 includes only Transport sub-sector assets within a traditional portfolio.

685 When building a multi-asset portfolio which includes Transport sub-sectors, Stocks, 686 Real Estate and Government Bonds, the maximum Sharp Index achieved is 0.428 and 
688 Bonds.

689

690 Figure 7. Optimal Portfolio in the Optimisation of the Transport sector

691

692

Government

\section{Bonds 17.7\%}

693

694 Similar to the two previous optimizations, the results are robust when undertaking the

695 M-CVaR optimization. When comparing the two efficient frontiers (Figure 8), we can

696 observe that the frontiers are very similar apart from the small differences observed at 697 the lower levels.

698

699 Figure 8. Efficient frontiers for Portfolios Mean-Variance and M-CVaR optimization 


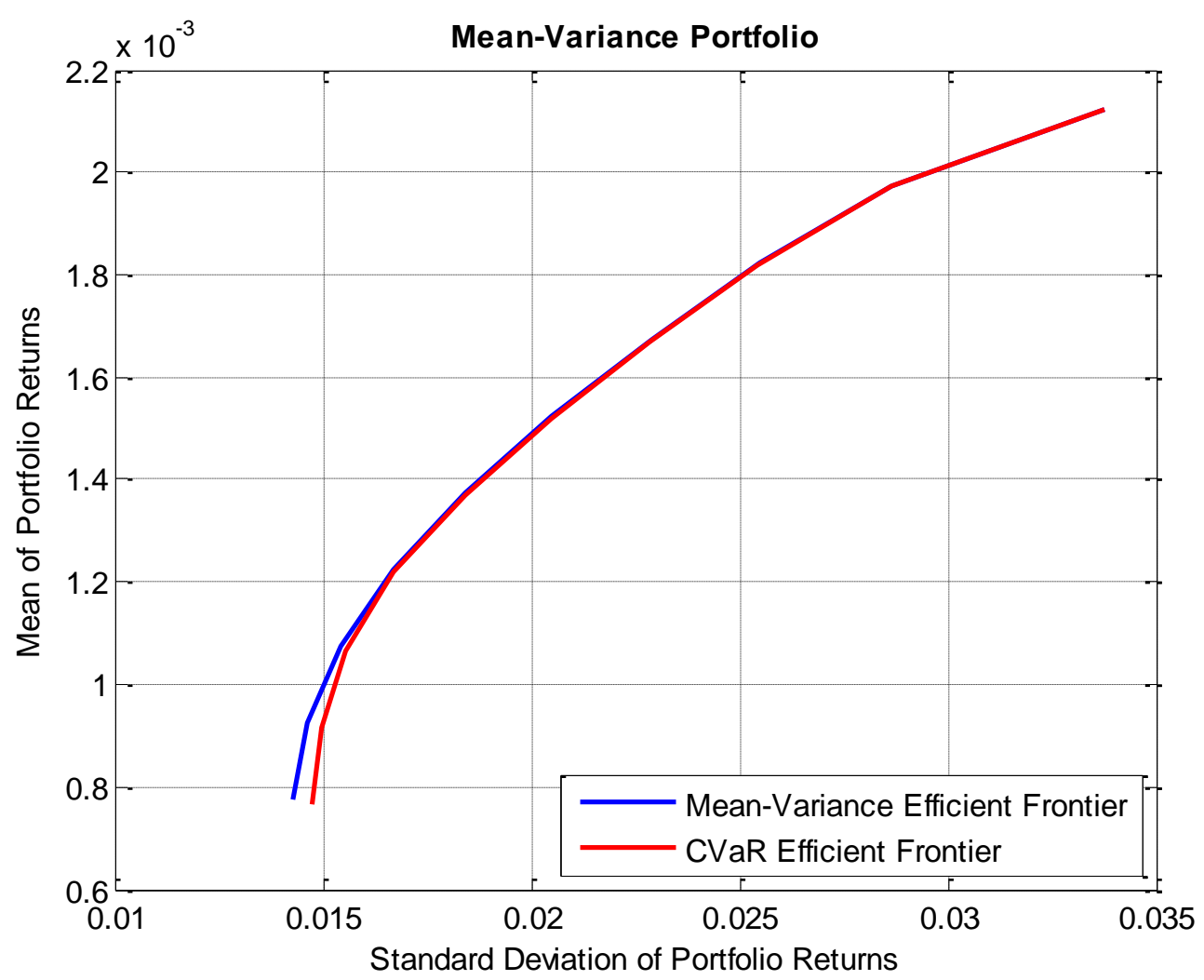

702 When comparing then the allocation of the assets in the two optimizations we observe

703 from Figure 9, that in the Mean-Variance portfolio weights more is invested in Toll 704 Roads and in Stocks relatively, to the CVaR Portfolio Weights. As can be seen from 705 the efficient frontiers portfolios in the Appendix, the differences in the allocation of 706 certain assets lie in the portfolios at the lower level of the risk/return ratio. However, 707 given the similarity of the results we certainly conclude that investor should only focus 708 and invest in a single sector.

710 Figure 9. Efficient frontiers for Portfolios Mean-Variance and M-CVaR optimization 

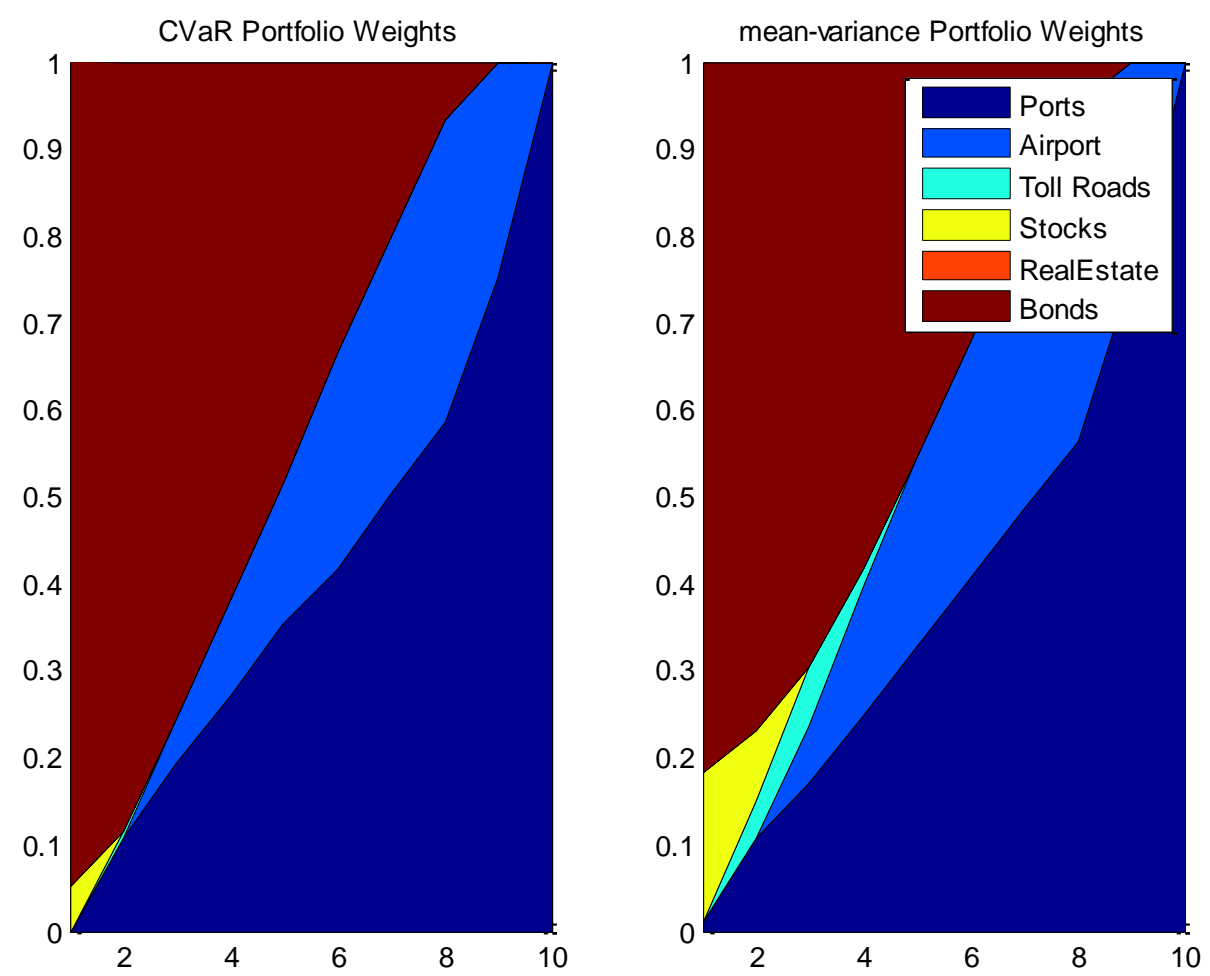

\section{Conclusions}

715 The importance of infrastructure to the economic welfare of countries is well-

716 recognised among economists, governments and policy makers. The provision of good

717 quality infrastructure is on the agenda of every European government, as infrastructure

718 is the path to increased living standards, economic growth and a means of escaping the

719 recession from which many European governments still suffer. However, the

720 importance of infrastructure investment not only rests with governments that turn to

721 infrastructure as a way to boost their economies. Institutional investors are also paying

722 close attention to infrastructure assets, particularly the European assets. According to

723 Preqin (2013), from the 3700 infrastructure deals that took place since 2008, an annual

724 average of $47 \%$ are deals made in European assets. 
726 Despite greater focus and attention being given to European infrastructure assets, little 727 research to date has examined the performance and portfolio implications of this asset 728 class. The economic importance and investment characteristics of infrastructure have 729 been studied mainly at the global level since the late 1980s, with minimal study of 730 different infrastructure sectors (Finkenzeller et al. 2010). As Oyedele (2013, p. 3) has 731 asserted, "infrastructure is an incorporation of many heterogeneous sectors including 732 roads, bridges, ports, power generation, electricity, gas utilities and 733 telecommunications with no two having identical attributes."

735 Due to the importance of European infrastructure assets in the global context, and the 736 existence of heterogeneity among different infrastructure sectors and sub-sectors, we 737 have in this paper evaluated the performance of different listed European economic 738 infrastructure assets, i.e., Energy, Utilities, Telecommunications, and Transport over a 739 period that also captures the effects of the financial crisis. The present paper has also 740 provided a performance analysis of Energy and Transport sub-sector indices as a way 741 to more closely scrutinise the behaviour differences and similarities of a selection of 742 sub-sectors. The paper has also examined the significance of including infrastructure in 743 a mixed asset portfolio and has attempted to determine the best way to construct and 744 invest in an infrastructure portfolio.

746 The results of the European analysis indicate that infrastructure sectors and sub-sectors 747 perform differently and show variations in annual returns and volatilities. In response, 748 greater attention should be paid to specific infrastructure sectors. Not only is knowledge 749 about the performance of different infrastructure sectors crucially important to fund 750 managers, but so is knowledge about each sub-sector equally vital. 
751 Our findings in the second part of the analysis conclude that when the infrastructure 752 sector is combined with other traditional assets, the portfolio yields a higher Sharp Index

753 than the Sharp Index that would be gained by investing in any single asset. Nonetheless,

754 the evidence presented in this study leads to our rejection of the proposition that listed 755 infrastructure can be treated as a separate asset class. We have determined that investing 756 in listed infrastructure is beneficial as long as it is a subset of a traditional portfolio. 757 Furthermore, according to the present research, the creation of a portfolio that invests in 758 a variety of infrastructure sectors is never an optimal solution. For this reason, we have 759 performed a sub-sector Transport and Energy portfolio analysis, and through this 760 analysis we can confirm that there are indeed diversification benefits, even within a 761 specific infrastructure sector.

763 The recent financial crisis has imposed strict constraints on the availability of public 764 funds, such that limited available resources must be spent as efficiently as possible; 765 governments are thereby required to select and prioritise among various infrastructure 766 projects (Szimba and Rothengatter 2012). This research has shown that, by focussing 767 on one listed infrastructure sector, a fund manager can gain complete knowledge of the 768 performance of the sector and still enjoy diversification benefits. An exciting 769 implication of this finding is that if a country lacks investment in one particular sector, 770 it can invest in this sector and still be able to diversify its infrastructure investment 771 portfolio.

\section{References}

774 Beeferman, W. (2008). "Pension Fund Investment in Infrastructure: A resource Paper." 775 Occasional Paper Series, 3, 1-78. 
777 Bianchi, R., Bornholt, G., Drew M. and Howard, M. (2014). "Long-term U.S.

778 infrastructure returns and portfolio selection" Journal of Banking \& Finance, 42,314779325.

780

781 Colonial First State Global Asset Management (CFS) (2010). “Unlisted Infrastructure:

782 A Proven Performer”. Infrastructure Research Note, London.

783

784

CSAM (2010). “Can Infrastructure Investing Enhance Portfolio Efficiency?” White 785 Paper, Crédit Suisse Asset Management, London.

786

787 Finkenzeller, K., Dechant, T. and Schafers, W. (2010). "Infrastructure: A new 788 Dimension of Real Estate? An Asset Allocation Analysis.” Journal of Property 789 Investment \& Finance, 28(4), 263-274.

790

791 Gomez, J. and Vasalo, J. (2014). "Comparative Analysis of Road Financing 792 Approaches in Europe and United States.” Journal of Infrastructure Systems, 20(3), 17938

794

795 Hall, J., Henriques, J., Hickford, A., Nicholls, R., Baruah, P., Birkin, M., Chaudry, M., 796 Curtis, T., Eyre, N., Jones, C., Kilsby, C., Leathard, A., Lorenz, A., Malleson, N., 797 McLeod, F., Powrie, W., Preston, J., Rai, N., Street, R., Stringfellow, A., Thoung, C., 798 Tyler, P., Velykiene, R., Watson, G., Watson, J. (2014). “Assessing the Long-Term 799 Performance of Cross-Sectoral Strategies for National Infrastructure." Journal of 800 Infrastructure Systems, 20(3), 1-11. 
802 Idzorek, T. and Armstrong, C. (2009). "Infrastructure and Strategic Asset Allocation:

803 Is Infrastructure an Asset Class?” Ibbotson Associates, Australia.

804

805 Inderst, G. (2009). "Pension Fund Investment in Infrastructure." Working Papers on

806 Insurance and Private Pensions No.32, Organisation for Economic Co-Operation and 807 Dependence.

808

809 Mackay-Fisher (2012). "Understanding Infrastructure Investments" CEO Forum, 810 Sydney.

811

812 Markowitz, H. (1955). "Portfolio Selection," Journal of Finance, 7(1) , 77-91.

813

814 Markowitz, H. (1959). “ Portfolio Selection: Efficient Diversification of

815 Investments", John Wiley \& Sons, Inc.

816

817 Morgan Stanley (2007) "Investing in Infrastructure: A Primer." Infrastructure Paper

818 Series, 2, Morgan Stanley Infrastructure Partners, New York.

819

820 Newell, G., Peng, H., and De Francesco, A. (2011). “The performance of unlisted

821 infrastructure in investment portfolios" Journal of Property Research, Special Issue:

822 Infrastructure and Regeneration 28(1), 59-74.

823

824 Newell, G. and Peng. H. (2007). "The Role of European Infrastructure in Investment 825 Portfolios.” European Real Estate Society (ERES) Conference London June 27-30. 
827 Oyedele, J., McGreal, S., Adair, A. and Ogedengbe, P. (2013). "Performance and Role 828 of European Listed Infrastructure in a Mixed-Asset Portfolio" Journal of Financial 829 Management of Property and Construction, 18(2), 160-183.

830

831 Oyedele, J. (2013). "Performance and Significance of UK listed infrastructure in a 832 Mixed Asset Portfolio" [pdf] See:

833 http://eres.architexturez.net/system/files/pdf/eres2013_14.content.pdf

834

835 Peng, H., and Newell, G. (2007). "The Significance of Infrastructure in Australian 836 Investment Portfolios.” Pacific Rim Real Estate Society Conference, 13(4),423-450.

837

838 Preqin (2014). Preqin Infrastructure Spotlight, September 2014, London.

839

840 Preqin (2013). Preqin Special Report: Infrastructure Transaction Activity, London. 841

842 Preqin. (2013). Preqin Special Report: European Infrastructure, London. 843

844 Rickards, D. (2008). “Global Infrastructure: A Growth Story found in Infrastructure 845 Finance: Trends and Techniques”. Edited by H.A. Davis, London, UK: Euromoney 846 Institutional Investor, Ch.1.

847

848 Rosenberg Real Estate Equity Funds (RREEF) (2007). "Performance Characteristics of 849 Infrastructure Investments.” San Francisco, California. 
851 Rockafellar, R. and Uryasev, S. (2000). "Optimization of Conditional Value-at-Risk," 852 Journal of Risk, 2(3), 21-41.

853

854 Rockafellar, R. and Uryasev, S. (2002) "Conditional Value-at-Risk for General Loss

855 Distributions," Journal of Banking and Finance, 26 , 1443-1471.

856

857 RREEF (2009). “Global Ports: Trends and Opportunities.” San Francisco, California. 858

859 RREEF (2010). “European Infrastructure Update July 2010.” San Francisco, 860 California.

861

862 RREEF (2011). “A Compelling Investment Opportunity: The Case July 2011 for

863 Global Listed Infrastructure Revisited.” San Francisco, California.

864

865 Russ, D., Thambiah, Y., and Foscari, N. (2010). "Can Infrastructure Investing Enhance 866 Portfolio Efficiency?” White Paper, Credit Suisse Asset Management, London.

867

868 Szimba, E. and Rothengatter, W. (2012). "Spending Scarce Funds More Efficiently:

869 Including the Pattern of Interdependence in Cost-Benefit Analysis." Journal of 870 Infrastructure Systems, 18(4), 242-251.

\section{Appendix}

873 Efficient frontier sets for all the portfolios

874 - Portfolio 1 includes only European traditional assets using Mean-Variance $875 \quad$ Optimisation 


\begin{tabular}{|r|r|r|r|r|r|}
\hline \multicolumn{1}{|l|}{$\begin{array}{l}\text { Portfolio } \\
\text { Volatility }\end{array}$} & \multicolumn{1}{l|}{$\begin{array}{l}\text { Stock } \\
\text { Bonds }\end{array}$} & \multicolumn{1}{l|}{$\begin{array}{l}\text { Real } \\
\text { Estate }\end{array}$} & $\begin{array}{l}\text { Portfolio } \\
\text { Return }\end{array}$ & Sharp Index \\
\hline $9.76 \%$ & $18.8 \%$ & $81.2 \%$ & $0 \%$ & $4.91 \%$ & 0.358 \\
\hline $10.1 \%$ & $6.23 \%$ & $93.8 \%$ & $0 \%$ & $5.27 \%$ & 0.384 \\
\hline $\mathbf{1 0 . 3 \%}$ & $\mathbf{0 \%}$ & $\mathbf{1 0 0 \%}$ & $\mathbf{0 \%}$ & $\mathbf{5 . 4 6 \%}$ & $\mathbf{0 . 3 9 2}$ \\
\hline $11.8 \%$ & $0 \%$ & $83.2 \%$ & $16.8 \%$ & $5.64 \%$ & 0.360 \\
\hline $13.8 \%$ & $0 \%$ & $66.5 \%$ & $33.5 \%$ & $5.83 \%$ & 0.321 \\
\hline $16.2 \%$ & $0 \%$ & $49.9 \%$ & $50.1 \%$ & $6.01 \%$ & 0.285 \\
\hline $18.8 \%$ & $0 \%$ & $33.3 \%$ & $66.7 \%$ & $6.19 \%$ & 0.254 \\
\hline $21.7 \%$ & $0 \%$ & $16.6 \%$ & $83.4 \%$ & $6.38 \%$ & 0.229 \\
\hline $24.5 \%$ & $0 \%$ & $0 \%$ & $100 \%$ & $6.56 \%$ & 0.210 \\
\hline
\end{tabular}

876

877 - Portfolio 2 includes the same assets as portfolio 1, plus the addition of all

878 infrastructure sectors using Mean-Variance Optimisation

\begin{tabular}{|r|r|r|r|r|r|r|r|r|r|}
\hline Portfolio Volatility & Energy & Telecom & Utilities & Transport & Stocks & $\begin{array}{l}\text { Real } \\
\text { Estate }\end{array}$ & $\begin{array}{l}\text { Govt. } \\
\text { Bonds }\end{array}$ & $\begin{array}{l}\text { Portfolio } \\
\text { Return }\end{array}$ & $\begin{array}{l}\text { Sharp } \\
\text { Index }\end{array}$ \\
\hline $9.76 \%$ & $0 \%$ & $0 \%$ & $0 \%$ & $0 \%$ & $18.8 \%$ & $0 \%$ & $81.2 \%$ & $4.91 \%$ & 0.358 \\
\hline $10.3 \%$ & $0 \%$ & $0 \%$ & $0 \%$ & $1.54 \%$ & $3.92 \%$ & $0 \%$ & $94.5 \%$ & $5.40 \%$ & 0.389 \\
\hline $11.2 \%$ & $0 \%$ & $0 \%$ & $0 \%$ & $11.3 \%$ & $0 \%$ & $0 \%$ & $88.7 \%$ & $5.90 \%$ & 0.400 \\
\hline $\mathbf{1 2 . 1 \%}$ & $\mathbf{0} \%$ & $\mathbf{0} \%$ & $\mathbf{0 \%}$ & $\mathbf{2 1 . 4 \%}$ & $\mathbf{0 \%}$ & $\mathbf{0 \%}$ & $\mathbf{7 8 . 6 \%}$ & $\mathbf{6 . 2 9 \%}$ & $\mathbf{0 . 4 0 2}$ \\
\hline $14.1 \%$ & $0 \%$ & $0 \%$ & $0 \%$ & $36.6 \%$ & $0 \%$ & $0 \%$ & $63.4 \%$ & $6.88 \%$ & 0.389 \\
\hline $15.8 \%$ & $0 \%$ & $0 \%$ & $0 \%$ & $49.3 \%$ & $0 \%$ & $0 \%$ & $50.7 \%$ & $7.38 \%$ & 0.377 \\
\hline $17.7 \%$ & $0 \%$ & $0 \%$ & $0 \%$ & $62.0 \%$ & $0 \%$ & $0 \%$ & $38.0 \%$ & $7.87 \%$ & 0.364 \\
\hline $19.8 \%$ & $0 \%$ & $0 \%$ & $0 \%$ & $74.7 \%$ & $0 \%$ & $0 \%$ & $25.3 \%$ & $8.36 \%$ & 0.352 \\
\hline $21.8 \%$ & $0 \%$ & $0 \%$ & $0 \%$ & $87.3 \%$ & $0 \%$ & $0 \%$ & $12.7 \%$ & $8.86 \%$ & 0.341 \\
\hline $23.8 \%$ & $0 \%$ & $0 \%$ & $0 \%$ & $100 \%$ & $0 \%$ & $0 \%$ & $0 . \%$ & $9.35 \%$ & 0.334 \\
\hline 879
\end{tabular}

879

$880 \quad-\quad$ Portfolio 2 includes the same assets as portfolio 1, plus the addition of all

881 infrastructure sectors using Mean Conditional Value-at-Risk

$882 \quad$ Optimisation

\begin{tabular}{|r|r|r|r|r|r|r|r|r|r|}
\hline \multicolumn{1}{|l|}{ Portfolio } & \multicolumn{1}{l|}{$\begin{array}{l}\text { Conditional } \\
\text { VaR }\end{array}$} & Energy & Telecom & Utilities & Transport & Stocks & $\begin{array}{l}\text { Real } \\
\text { Estate }\end{array}$ & \multicolumn{2}{l|}{$\begin{array}{l}\text { Bortfolio } \\
\text { Return }\end{array}$} \\
\hline $10.0 \%$ & 0.070 & $0 \%$ & $0 \%$ & $0 \%$ & $0.0 \%$ & $7.40 \%$ & $0 \%$ & $92.6 \%$ & $5.24 \%$ \\
\hline $10.8 \%$ & 0.075 & $0 \%$ & $0 \%$ & $0 \%$ & $6.20 \%$ & $0 \%$ & $0 \%$ & $93.8 \%$ & $5.70 \%$ \\
\hline $11.9 \%$ & 0.084 & $0 \%$ & $0 \%$ & $0 \%$ & $17.9 \%$ & $0 \%$ & $0 \%$ & $82.1 \%$ & $6.15 \%$ \\
\hline $13.2 \%$ & 0.094 & $0 \%$ & $0 \%$ & $0 \%$ & $29.7 \%$ & $0 \%$ & $0 \%$ & $70.3 \%$ & $6.61 \%$ \\
\hline $14.7 \%$ & 0.105 & $0 \%$ & $0 \%$ & $0 \%$ & $41.4 \%$ & $0 \%$ & $0 \%$ & $58.6 \%$ & $7.07 \%$ \\
\hline $16.4 \%$ & 0.118 & $0 \%$ & $0 \%$ & $0 \%$ & $53.1 \%$ & $0 \%$ & $0 \%$ & $46.9 \%$ & $7.52 \%$ \\
\hline $18.2 \%$ & 0.132 & $0 \%$ & $0 \%$ & $0 \%$ & $64.8 \%$ & $0 \%$ & $0 \%$ & $35.2 \%$ & $7.98 \%$ \\
\hline
\end{tabular}




\begin{tabular}{|r|r|r|r|r|r|r|r|r|r|}
\hline $20.1 \%$ & 0.146 & $0 \%$ & $0 \%$ & $0 \%$ & $76.6 \%$ & $0 \%$ & $0 \%$ & $23.4 \%$ & $8.44 \%$ \\
\hline $22.0 \%$ & 0.159 & $0 \%$ & $0 \%$ & $0 \%$ & $88.3 \%$ & $0 \%$ & $0 \%$ & $11.7 \%$ & $8.90 \%$ \\
\hline $23.8 \%$ & 0.173 & $0 \%$ & $0 \%$ & $0 \%$ & $100 \%$ & $0 \%$ & $0 \%$ & $0.0 \%$ & $9.35 \%$ \\
\hline
\end{tabular}

883

884 - Portfolio 3 specialises only in the energy sub-sector assets (Natural Gas,

885 Electricity, Fossil fuels, Renewable Energy) within a traditional portfolio

886 using the Mean-Variance Optimisation

\begin{tabular}{|l|l|l|l|l|l|l|l|l|l|}
\hline $\begin{array}{l}\text { Portfolio } \\
\text { Volatility }\end{array}$ & $\begin{array}{l}\text { Fossil } \\
\text { Fuels }\end{array}$ & $\begin{array}{l}\text { Renewable } \\
\text { Energy }\end{array}$ & $\begin{array}{l}\text { Natural } \\
\text { Gas }\end{array}$ & Electricity & Stocks & $\begin{array}{l}\text { Real } \\
\text { Estate }\end{array}$ & $\begin{array}{l}\text { Govt. } \\
\text { Bonds }\end{array}$ & $\begin{array}{l}\text { Portfolio } \\
\text { Return }\end{array}$ & $\begin{array}{l}\text { Sharp } \\
\text { Index }\end{array}$ \\
\hline $10.0 \%$ & $0 \%$ & $0 \%$ & $6.36 \%$ & $2.49 \%$ & $14.6 \%$ & $0 \%$ & $76.6 \%$ & $4.16 \%$ & 0.249 \\
\hline $10.1 \%$ & $0 \%$ & $0 \%$ & $7.18 \%$ & $11.6 \%$ & $6.31 \%$ & $0 \%$ & $74.9 \%$ & $4.44 \%$ & 0.276 \\
\hline $10.3 \%$ & $0 \%$ & $0 \%$ & $7.70 \%$ & $21.2 \%$ & $0 \%$ & $0 \%$ & $71.1 \%$ & $4.73 \%$ & 0.299 \\
\hline $\mathbf{1 0 . 8 \%}$ & $\mathbf{0 \%}$ & $\mathbf{0 \%}$ & $\mathbf{7 . 2 9 \%}$ & $\mathbf{3 2 . 1 \%}$ & $\mathbf{0 \%}$ & $\mathbf{0 \%}$ & $\mathbf{6 0 . 6 \%}$ & $\mathbf{5 . 0 2 \%}$ & $\mathbf{0 . 3 1 1}$ \\
\hline $11.7 \%$ & $0 \%$ & $0 \%$ & $6.87 \%$ & $43.1 \%$ & $0 \%$ & $0 \%$ & $50.0 \%$ & $5.30 \%$ & 0.311 \\
\hline $13.0 \%$ & $0 \%$ & $0 \%$ & $6.46 \%$ & $54.0 \%$ & $0 \%$ & $0 \%$ & $39.5 \%$ & $5.59 \%$ & 0.303 \\
\hline $14.4 \%$ & $0 \%$ & $0 \%$ & $6.05 \%$ & $65.0 \%$ & $0 \%$ & $0 \%$ & $29.0 \%$ & $5.87 \%$ & 0.292 \\
\hline $16.1 \%$ & $0 \%$ & $0 \%$ & $5.63 \%$ & $76.0 \%$ & $0 \%$ & $0 \%$ & $18.4 \%$ & $6.16 \%$ & 0.280 \\
\hline $17.8 \%$ & $0 \%$ & $0 \%$ & $5.22 \%$ & $86.9 \%$ & $0 \%$ & $0 \%$ & $7.87 \%$ & $6.44 \%$ & 0.268 \\
\hline $19.7 \%$ & $0 \%$ & $0 \%$ & $0 \%$ & $100 \%$ & $0 \%$ & $0 \%$ & $0 \%$ & $6.74 \%$ & 0.258 \\
\hline
\end{tabular}

887

888 - Portfolio 3 specialises only in the energy sub-sector assets (Natural Gas,

889 Electricity, Fossil fuels, Renewable Energy) within a traditional portfolio

$890 \quad$ using the Mean- Conditional Value-at-Risk Optimisation

891

\begin{tabular}{|l|l|l|l|l|l|l|l|l|l|}
\hline Volatility & C-VaR & $\begin{array}{l}\text { Fossil } \\
\text { Fuels }\end{array}$ & $\begin{array}{l}\text { Renewable } \\
\text { Energy }\end{array}$ & $\begin{array}{l}\text { Natural } \\
\text { Gas }\end{array}$ & Electricity & Stocks & $\begin{array}{l}\text { Real } \\
\text { Estate }\end{array}$ & $\begin{array}{l}\text { Government } \\
\text { Bonds }\end{array}$ & Return \\
\hline $10.2 \%$ & 0.033 & $0 \%$ & $0 \%$ & $11.8 \%$ & $2.83 \%$ & $3.81 \%$ & $0 \%$ & $81.6 \%$ & $4.28 \%$ \\
\hline $10.2 \%$ & 0.033 & $0 \%$ & $0 \%$ & $14.5 \%$ & $11.3 \%$ & $0 \%$ & $0 \%$ & $74.2 \%$ & $4.55 \%$ \\
\hline $10.5 \%$ & 0.035 & $0 \%$ & $0 \%$ & $15.9 \%$ & $21.0 \%$ & $0 \%$ & $0 \%$ & $63.1 \%$ & $4.82 \%$ \\
\hline $11.1 \%$ & 0.037 & $0 \%$ & $0 \%$ & $14.6 \%$ & $31.8 \%$ & $0 \%$ & $0 \%$ & $53.6 \%$ & $5.09 \%$ \\
\hline $12.1 \%$ & 0.041 & $0 \%$ & $0 \%$ & $15.5 \%$ & $41.7 \%$ & $0 \%$ & $0 \%$ & $42.8 \%$ & $5.37 \%$ \\
\hline $13.3 \%$ & 0.045 & $0 \%$ & $0 \%$ & $13.1 \%$ & $53.1 \%$ & $0 \%$ & $0 \%$ & $33.9 \%$ & $5.64 \%$ \\
\hline $14.7 \%$ & 0.050 & $0 \%$ & $0 \%$ & $14.8 \%$ & $62.6 \%$ & $0 \%$ & $0 \%$ & $22.6 \%$ & $5.91 \%$ \\
\hline $16.3 \%$ & 0.056 & $0 \%$ & $0 \%$ & $13.3 \%$ & $73.5 \%$ & $0 \%$ & $0 \%$ & $13.2 \%$ & $6.18 \%$ \\
\hline $18.0 \%$ & 0.061 & $0 \%$ & $0 \%$ & $14.3 \%$ & $83.4 \%$ & $0 \%$ & $0 \%$ & $2.35 \%$ & $6.46 \%$ \\
\hline $19.7 \%$ & 0.068 & $0 \%$ & $0 \%$ & $0 \%$ & $100 \%$ & $0 \%$ & $0 \%$ & $0 \%$ & $6.74 \%$ \\
\hline
\end{tabular}


892 - Portfolio 4 includes Transport sub-sector assets (Airports, Ports, and Toll

893 Roads) within a traditional portfolio using Mean-Variance Optimisation

894

\begin{tabular}{|c|c|c|c|c|c|c|c|c|}
\hline $\begin{array}{l}\text { Portfolio } \\
\text { Volatility } \\
\end{array}$ & Ports & Airports & $\begin{array}{l}\text { Toll } \\
\text { Roads }\end{array}$ & Stocks & \begin{tabular}{|l} 
Real \\
Estate \\
\end{tabular} & Bonds & Portfolio Return & $\begin{array}{l}\text { Sharp } \\
\text { Index }\end{array}$ \\
\hline $10.3 \%$ & $1.17 \%$ & $0 \%$ & $0 \%$ & $17.2 \%$ & $0 \%$ & $81.6 \%$ & $4.03 \%$ & 0.230 \\
\hline $10.5 \%$ & $10.7 \%$ & $0 \%$ & $4.22 \%$ & $8.19 \%$ & $0 \%$ & $76.9 \%$ & $4.80 \%$ & 0.299 \\
\hline $11.1 \%$ & $17.0 \%$ & $6.65 \%$ & $6.75 \%$ & $0 \%$ & $0 \%$ & $69.6 \%$ & $5.58 \%$ & 0.353 \\
\hline $12.0 \%$ & $24.8 \%$ & $14.9 \%$ & $1.84 \%$ & $0 \%$ & $0 \%$ & $58.4 \%$ & $6.36 \%$ & 0.391 \\
\hline $13.3 \%$ & $32.7 \%$ & $21.6 \%$ & $0 \%$ & $0 \%$ & $0 \%$ & $45.7 \%$ & $7.14 \%$ & 0.413 \\
\hline $14.8 \%$ & $40.6 \%$ & $27.3 \%$ & $0 \%$ & $0 \%$ & $0 \%$ & $32.1 \%$ & $7.92 \%$ & 0.424 \\
\hline $16.6 \%$ & $48.9 \%$ & $33.4 \%$ & $0 \%$ & $0 \%$ & $0 \%$ & $17.7 \%$ & $8.76 \%$ & 0.428 \\
\hline $18.3 \%$ & $56.4 \%$ & $38.8 \%$ & $0 \%$ & $0 \%$ & $0 \%$ & $4.81 \%$ & $9.48 \%$ & 0.426 \\
\hline $20.7 \%$ & $75.2 \%$ & $24.8 \%$ & $0 \%$ & $0 \%$ & $0 \%$ & $0 \%$ & $10.3 \%$ & 0.416 \\
\hline $24.3 \%$ & $100 \%$ & $0 \%$ & $0 \%$ & $0 \%$ & $0 \%$ & $0 \%$ & $11.1 \%$ & 0.386 \\
\hline
\end{tabular}

895

896 - Portfolio 4 includes Transport sub-sector assets (Airports, Ports, and Toll

897 Roads) within a traditional portfolio using Mean- Conditional Value at Risk

$898 \quad$ Optimisation

899

\begin{tabular}{|l|l|l|l|l|l|l|l|l|}
\hline $\begin{array}{l}\text { Portfolio } \\
\text { Volatility }\end{array}$ & C-VaR & Ports & Airports & $\begin{array}{l}\text { Toll } \\
\text { Roads }\end{array}$ & Stocks & $\begin{array}{l}\text { Real } \\
\text { Estate }\end{array}$ & Bonds & $\begin{array}{l}\text { Portfolio } \\
\text { Return }\end{array}$ \\
\hline $10.6 \%$ & 0.034 & $0 \%$ & $0 \%$ & $0 \%$ & $5.1 \%$ & $0 \%$ & $94.9 \%$ & $3.98 \%$ \\
\hline $10.8 \%$ & 0.035 & $10.7 \%$ & $0 \%$ & $0.8 \%$ & $0 \%$ & $0 \%$ & $88.5 \%$ & $4.77 \%$ \\
\hline $11.2 \%$ & 0.038 & $19.3 \%$ & $4.98 \%$ & $0 \%$ & $0 \%$ & $0 \%$ & $75.7 \%$ & $5.55 \%$ \\
\hline $12.0 \%$ & 0.041 & $27.1 \%$ & $11.0 \%$ & $0 \%$ & $0 \%$ & $0 \%$ & $61.9 \%$ & $6.33 \%$ \\
\hline $13.3 \%$ & 0.045 & $35.3 \%$ & $16.3 \%$ & $0 \%$ & $0 \%$ & $0 \%$ & $48.4 \%$ & $7.12 \%$ \\
\hline $14.7 \%$ & 0.051 & $41.7 \%$ & $24.8 \%$ & $0 \%$ & $0 \%$ & $0 \%$ & $33.5 \%$ & $7.90 \%$ \\
\hline $16.5 \%$ & 0.057 & $50.3 \%$ & $29.4 \%$ & $0 \%$ & $0 \%$ & $0 \%$ & $20.3 \%$ & $8.68 \%$ \\
\hline $18.3 \%$ & 0.064 & $58.5 \%$ & $34.8 \%$ & $0 \%$ & $0 \%$ & $0 \%$ & $6.7 \%$ & $9.47 \%$ \\
\hline $20.6 \%$ & 0.071 & $75.1 \%$ & $24.9 \%$ & $0 \%$ & $0 \%$ & $0 \%$ & $0 \%$ & $10.3 \%$ \\
\hline $24.3 \%$ & 0.084 & $100 \%$ & $0 \%$ & $0 \%$ & $0 \%$ & $0 \%$ & $0 \%$ & $11.1 \%$ \\
\hline
\end{tabular}

900 